\title{
'ISFMÜNCHEN
}

Themenfeld

\section{Flexibilisierung und Subjektivierung von Arbeit}

Nick Kratzer, Dieter Sauer, Anne Hacket, Katrin Trinks (ISF München) unter Mitarbeit von Alexandra Wagner 
Inhalt

Einleitung

1. FLEXIBILISIERUNG UND SUBJEKTIVIERUNG ALS KATEGORIEN DER BERICHTERSTATTUNG.

1.1 FLEXIBILISIERUNG UND SUBJEKTIVIERUNG ALS DIMENSIONEN EINES NEUEN RATIONALISIERUNGSMODUS .5

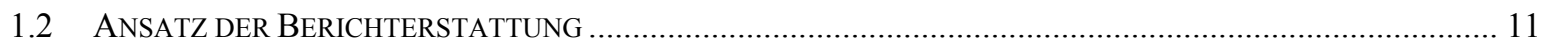

2. FLEXIBILISIERUNG DER BESCHÄFTIGUNG ……......................................................................... 14

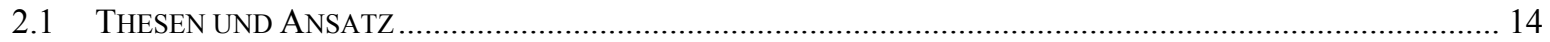

2.2 BEFUNDE ZUR FLEXIBILISIERUNG DER BESCHÄFTIGUNG ......................................................................... 20

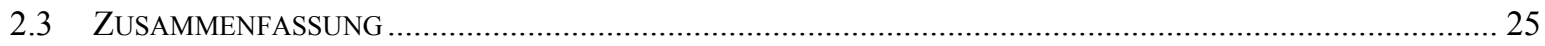

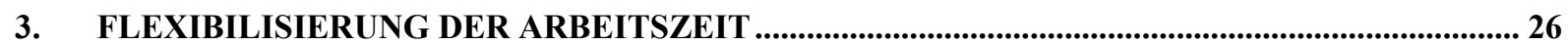

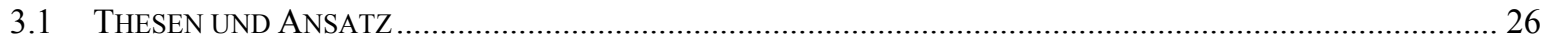

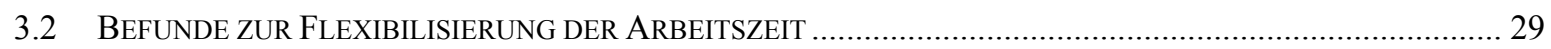

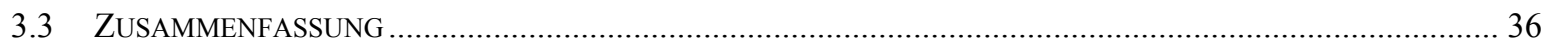

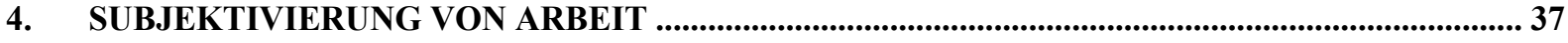

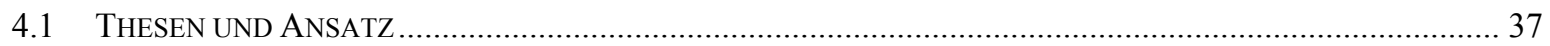

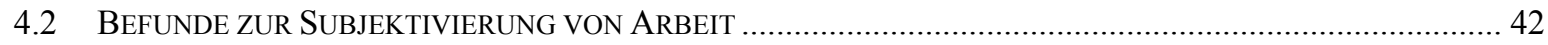

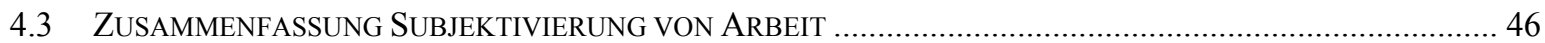

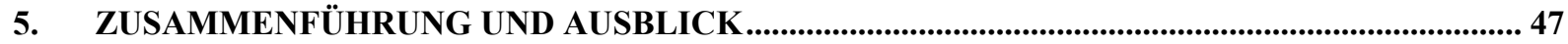

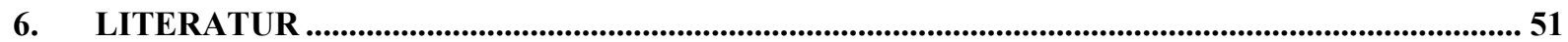




\section{Einleitung}

Spätestens seit die Vorstellung einer ,immerwährenden Prosperität“ als „kurzer Traum“ (Lutz 1984) identifiziert und die „Krise der Arbeitsgesellschaft“ (Matthes 1982) ausgerufen wurde, hatte die arbeits- und industriesoziologische Diskussion ein neues Thema: Die Krise des fordistischen Produktions- und Sozialmodells, das möglicherweise herannahende Ende jener institutionellen Arrangements, die bis heute in normativer und struktureller Hinsicht prägend sind. Den Stoff für das Drehbuch eines grundlegenden Wandels liefern ökonomische wie gesellschaftliche Entwicklungsprozesse gleichermaßen: Globalisierung, Tertiarisierung oder Informatisierung; neue Arbeitsformen und Beschäftigungsverhältnisse (Flexibilisierung, Selbstorganisation); Wertewandel und veränderte Orientierungsmuster („,normative Subjektivierung"); neue soziale Bewegungen; Individualisierung und Auflösung traditioneller Familienstrukturen; Infragestellung der geschlechtsspezifischen Segregation von Lebensbereichen und wachsende Erwerbsbeteiligung von Frauen; Massenarbeitslosigkeit und „plurale Unterbeschäftigung“; „Krise des Wohlfahrtsstaates“; De-Regulierung und neoliberale Wirschaftspolitik u.a.

Während sich die Vorstellung von einem grundlegenden Wandel des fordistischen Produktions- und Sozialmodells zunächst daran festmachte, daß die ,(Erwerbs-)Arbeitsgesellschaft“ als dessen konstitutive Basis in der Krise, am „Ende“ sei, $^{1}$ ist es in der neueren Diskussion gerade die Entwicklung von Arbeit, die für die These eines Umbruchs grundlegend ist. Insbesondere drei Entwicklungen finden in der arbeits- und industriesoziologischen Diskussion breite Beachtung als Indizien eines Umbruchs. Zum einen sind dies Hinweise auf tiefgreifende Veränderungen der Unternehmensorganisation und der Organisation von Arbeit: Systemische Rationalisierung, Neue Produktionskonzepte, lean production, Dezentralisierung und Vermarktlichung, indirekte Steuerung und Selbstorganisation. Zum zweiten sind dies Hinweise auf eine zunehmende Flexibilisierung von Arbeit (im Hinblick auf das Beschäftigungsverhältnis, die Arbeitszeit, die Qualifikationsanforderungen, den Arbeitsort, die Erwerbsbiographie u.a.). Zum dritten sind dies die Hinweise auf eine wachsende Verbreitung neuer Arbeitsformen (etwa Projekt- oder Gruppenarbeit) und neuer leistungspolitischer Konzepte (Indirekte Steuerung etwa durch Zielvereinbarungen, leistungsorientierte Entgelte, Vertrauensarbeitszeit,

1 So etwa: „Nicht nur objektiv ist die Arbeit aus ihrem Status als einer zentralen und selbstverständlichen Lebenstatsache verdrängt worden, sondern auch subjektiv hat sie - im Einklang mit dieser objektiven Entwicklung, aber in Diskrepanz zu den offiziellen Werten und Legitimationsmustern der Gesellschaft - diesen Status im Motivhaushalt der Arbeitenden eingebüßt“"(Offe 1982, S. 57). 
Selbstorganisation u.a.). Von einem Umbruch ist hier deshalb die Rede, weil damit zugleich grundlegende Strukturprinzipien der fordistisch-tayloristischen Regulation von Arbeit zur Disposition stehen, deren „Erosion“ nicht auf die Welt der Arbeit im engeren Sinne beschränkt bleibt, sondern auch die übergreifenden institutionellen Arrangements von Bildungssystem, Familienstrukturen, Lebensweisen, Konsumstilen usw. berührt: Die Flexibilisierung von Arbeit hebt - als Tendenz - die Scheidung von Arbeit einerseits und (privatem) Leben andererseits auf, flexible Beschäftigungsverhältnisse stellen die Strukturierung der Arbeitsmärkte entlang von Betriebszugehörigkeit und Beruf in Frage, die neuen Organisations- und Steuerungsformen von Arbeit stellen die innerbetriebliche Differenzierung zwischen Unternehmer und Arbeitnehmer, zwischen Management und Beschäftigen ebenso in Frage wie sie die Logik der fortschreitenden „Objektivierung“ menschlicher Arbeit geradezu umzudrehen scheinen: Deshalb fassen einige - so auch wir - solche Entwicklungstendenzen auch als „Subjektivierung“ von Arbeit, da es, wie Moldaschl und Voß betonen, „derzeit (...) um etwas anderes geht: Nämlich um eine im Vergleich mit der bisher vorherrschenden Logik kapitalistischer Nutzung von Arbeitskraft sich neu formierende und erweiternde Verwertung der ,Subjektivität‘ von Arbeitenden für betriebliche Zwecke“(Moldaschl, Voß 2002).

So prominent und vielbeachtet diese Entwicklungstendenzen sind - unbestritten sind sie nicht: Kaum jemand wird leugnen, $d a \beta$ es Prozesse einer Flexibilisierung und Subjektivierung von Arbeit gibt, aber: Sind sie Anzeichen eines Umbruchs oder von Entwicklungen, die letztlich in der Kontinuität des Produktions- und Sozialmodells verbleiben? Inwiefern kann in quantitativer Hinsicht von einem Umbruch die Rede sein? Noch kaum geklärt ist auch die Frage der Heterogenität dieser Prozesse und wie sich diese zu vertrauten Segmentationslinien und Differenzierungskriterien verhält. Klärungsbedarf besteht ebenfalls noch hinsichtlich der „qualitativen“ Aspekte einer Flexibilisierung und Subjektivierung von Arbeit, so insbesondere: Welche - neue oder veränderte - „Logik“ der Organisation von Arbeit kommt hier zum Ausdruck? Wie korrespondiert diese mit gesellschaftlichen Entwicklungstendenzen? Mit welchen Chancen oder Risiken insbesondere für Arbeitskräfte verbindet sie sich und wie verändert sich vor diesem Hintergrund das Verhältnis von Arbeit und Lebensweisen? Letztere Frage ist von herausragender Bedeutung, da die bisherigen Diagnosen und Analysen eher von einer ambivalenten Entwicklung ausgehen, einer Entwicklung, die sowohl „Modernisierungsgewinner“ wie auch „Modernisierungsverlierer“, neue Chancen wie neue Risiken kennt (vgl. Kratzer 2002; Moldaschl, Voß 2002; Schumann 2001; Zilian 2000). 


\section{Flexibilisierung und Subjektivierung als Kategorien der Berichterstattung}

Das Themenfeld stellt Veränderungstendenzen in der betrieblichen Organisation von Arbeit in den Mittelpunkt. Damit wird eine spezifische Ebene des gesellschaftlichen Wandels thematisiert, die in doppelter Hinsicht eine Vermittlungsebene darstellt: Sie ist einerseits Mesoebene im Sinne einer Vermittlungsebene zwischen der Makroebene ökonomischer Prozesse und gesellschaftlicher Regulierung und der Mikroebene der individuellen Lebenswelt. Zugleich kommt ihr auch in gewissermaßen horizontaler Perspektive Vermittlungscharakter zu: zwischen einerseits ökonomischen und andererseits gesellschaftlichen Entwicklungstendenzen. Die betriebliche Organisation von Arbeit kann jeweils als das Ergebnis einerseits ökonomischer „Restrukturierungstrends“ sowie unternehmerischer (Re-)Aktionen (Reorganisation der Unternehmen) und andererseits der gesellschaftlichen Einflußfaktoren (institutionelle Regulierung von Arbeit, quantitative und qualitative Struktur des (regionalen) Arbeitskräfteangebotes, Familien- und Haushaltsstrukturen, Arbeits- und Erwerbsorientierungen u.a.) verstanden werden.

Flexibilisierung und Subjektivierung von Arbeit betrachten wir gegenwärtig als die beiden zentralen Entwicklungstendenzen, an denen sich die Frage des Umbruchs in der gesellschaftlichen Organisation von Arbeit und seine Richtung und Reichweite festmachen lassen. Für die Beantwortung der Frage, was jeweils neu an den empirisch vorgefundenen Veränderungen ist, und auch für die Frage, welche Bedeutung ihnen zukünftig zukommen wird, halten wir es für wichtig, diese Veränderung von Arbeitsformen immer in einer doppelten Weise zu analysieren: Zum einen als Veränderung betrieblicher Reorganisation und Rationalisierungspolitik und der dahinter stehenden ökonomischen Restrukturierungstendenzen und zum anderen als Veränderungen der individuellen Arbeits- und Lebensbedingungen, der Orientierungen und Interessenlagen der Beschäftigten. Nur wenn diese beiden Seiten empirisch wie theoretisch aufeinander bezogen werden, erschließt sich über die Konstatierung empirischer Phänomene hinaus die innere Logik und damit auch die historische Relevanz dieser Entwicklung von Arbeit.

\subsection{Flexibilisierung und Subjektivierung als Dimensionen eines neuen Ratio- nalisierungsmodus}

Auf der Ebene der unmittelbaren Organisation von Beschäftigung und Arbeit läßt sich komplementär zu den Tendenzen der ökonomischen Restrukturierung und der Reorganisation von 
Unternehmen (vgl. dazu den Berichtsgegenstand „Unternehmens- und Arbeitsorganisation“) ein Umbruch betrieblicher Rationalisierung konstatieren, den wir - vorläufig - als einen neuen Modus der Organisation von Unbestimmtheit fassen: Anders als in der - idealtypisch betrachteten - fordistischen Unternehmensorganisation gilt somit nun nicht länger das Prinzip der weitgehenden Abschottung der Produktionsökonomie von der Marktökonomie und der Transformation externer (marktlicher) Unbestimmtheit in interne Bestimmtheit, sondern gerade das Gegenteil ist der Fall: Die Organisation ist nicht mehr auf die Organisation von Bestimmtheit getrimmt, die Unbestimmtheit marktlicher Anforderungen wird nicht nur explizit zugelassen, sondern selbst zum Organisationsprinzip. Nun wird betrieblich nicht mehr Bestimmtheit organisiert, sondern - überspitzt formuliert - Unbestimmtheit:

Arbeitsorganisatorisch erweisen sich standardisierte Arbeitsvorgaben, Kollektive als Bezugspunkt der Einsatzorganisation, die normierte Verfügbarkeit von Arbeitskraft und eingeschränkte Handlungs- und Entscheidungsspielräume sowie mehr oder weniger rigide Kontrollen als immer weniger geeignet, die nun gleichsam internalisierte Unbestimmthei zu bewältigen. Die (neue) Antwort ist: Indirekte Steuerung und Selbstorganisation. Indirekte Steuerung bedeutet als Prinzip, daß externe Anforderungen nun unmittelbarer, d.h. ohne den Durchgang durch zentrale „Rationalisierungsstäbe“ an die dezentralen Einheiten bzw. die Beschäftigten weitergeleitet werden. ${ }^{2}$ Indirekte Steuerung bedeutet jedoch nicht den vollständigen Verzicht auf Steuerung, sondern deren Formwandel, weil Steuerung nun nicht mehr durch kleinschrittige Vorgaben und Kontrollen, sondern über die Bestimmung des „Kontextes“ individueller Arbeitsverausgabung, d.h. über die Festlegung der Rahmenbedingungen (Personalressourcen, Anlagen, Investitionen etc.) sowie über die Setzung (und Kontrolle) von Zielvorgaben (Kosten-, Umsatz- oder Ertragsziele, Termine, Marktanteile, Benchmarks etc.) erfolgt. Selbstorganisation ist in diesem Zusammenhang der komplementäre Modus der Organisation dezentraler Einheiten und individueller Arbeit: Selbstorganisation bedeutet im Kern, daß die Bewältigung von Unbestimmtheit nun mehr und mehr zur Aufgabe der Beschäftigten (oder von Arbeitsgruppen etc.) wird.

Vgl. zum Folgenden auch Faust u.a.: „Die untersuchten Organisationsveränderungen lassen sich (...) als Umkehr des Trends zur Verlagerung von Unsicherheitsbewältigung aus der herstellenden Arbeit (...) in spezialisierte Dienstleistungsstäbe, d.h. als Zeichen eines neuen Trends zur Reintegration von Herstellungs- und Gewährleistungs- bzw. industrieller Dienstleistungsarbeit verstehen. Diese Reintegration kann (...) in verschiedenen Formen erfolgen: Einmal vornehmlich in Form der Reintegration unmittelbar in herstellende Arbeitstätigkeiten (arbeitsorganisatorische Reintegration im engeren Sinn) und zum anderen vornehmlich in Form der Reintegration in dezentrale Produktionseinheiten (betriebsorganisatorische Form)“ (Faust u.a. 1994, S. 201). 
Dies wiederum setzt spezifische Veränderungen der Arbeits- und Beschäftigungsorganisation voraus: Die organisatorische Flexibilisierung des Arbeitseinsatzes (flexible Beschäftigung, neue Arbeitszeitmodelle, räumliche Flexibilisierung etc.), den Abbau von Hierarchiestufen, die Übertragung von Gestaltungs- und Entscheidungsfreiheiten auf Gruppen oder Individuen, die Implementation von Arbeitsformen, die offener und flexibler gegenüber variablen Anforderungen sind sowie Selbstorganisation explizit ermöglichen (Projektarbeit, Gruppenarbeit, Zielvereinbarungen etc.). ${ }^{3}$ Die Flexibilisierung des Einsatzes und die Subjektivierung der Nutzung von Arbeitskraft sind somit wesentliche Bausteine neuer Strategien zur Bewältigung nun internalisierter Unbestimmtheit.

Auf der unmittelbaren Arbeitsebene besteht die entscheidende Konsequenz in der erweiterten Verwertung, man könnte sagen: „Inbetriebnahme“, der subjektiven Potentiale und lebensweltlichen Ressourcen von Arbeitskraft. Unbestimmtheit subjektiv bewältigen heißt: Das aufwendige Geschäft der Transformation von Arbeitsvermögen in Arbeitsleistung selbst in die Hand zu nehmen - und das sowohl als Subjekt, d.h. als Akteur der (Selbst)Rationalisierung wie auch als Objekt der Rationalisierung. ${ }^{4}$ Als (notwendige) Gegenleistung erhalten sie erweiterte Handlungs- und Entscheidungsspielräume, die sich sowohl auf die Arbeitssphäre als auch auf das Verhältnis von Arbeitswelt und Lebenswelt erstrecken. In der Perspektive eines Umbruchs betrieblicher Rationalisierungsstrategien besteht demnach das wesentliche Merkmal selbstorganisierter und flexibilisierter Arbeit im erweiterten Subjektbezug der Rationalisierung: Das einzelne Subjekt tritt - neben dem Betrieb - als neuer Rationalisierungsakteur auf den Plan und zugleich wird Subjektivität zum einem wesentlichen Bezugspunkt der Rationalisierung in zweifacher Hinsicht: Als spezifisches arbeitsinhaltliches Potential (Kreativität, soziale Kompetenz, Gefühl, Motivation etc.) wie als spezifisches - und eben hochelastisches - Potential zur Organisation und Steuerung von Arbeit. Die Ambivalenz entgrenzter Arbeit rührt aus der erweiterten Autonomie des Subjekts bei eben gleichzeitig erweitertem Verwertungsanspruch, genauso aber auch aus der ambivalenten Figur des nun entstehenden ,gespaltenen Subjekts“ (Böhle 2002), einem Subjekt, das sich selbst zum Objekt wird (und werden muß), das nun vor einer neuen Aufgabe steht: Der „Herstellung und Ent-

Vgl. dazu auch Schumann, Gerst 1998; Bollinger 2001; Bender 2002.

4 Das Konzept des „Arbeitskraftunternehmers“ stellt genau hierauf ab: Die Arbeitssubjekte werden zu Unternehmen ihrer eigenen Arbeitskraft und zunehmend gezwungen, Arbeitsverausgabung, Vermarktung sowie Lebensführung zweckrational, d.h. mit Blick auf den Verwertungsprozeß und die Verwertung von Arbeitskraft zu organisieren (Voß, Pongratz 1998; Voß 1998). 
wicklung eines ,inneren Produktionsverhältnisses ' der eigenen Arbeitskraft als Ware durch das Individuum ,zu sich selbst als Lebewesen“(Bechtle, Sauer 2001, S. 94).

Somit setzt die unmittelbarere Konfrontation der Beschäftigten mit der marktlichen Umwelt der Unternehmen in der Folge erodierender Grenzen des Unternehmens diese der Unbestimmtheit der Umwelt aus und zugleich in erweiterter Weise die Unbestimmtheit ihrer Verausgabung voraus. Neu ist daran nicht, daß bei der Bewältigung von Unbestimmtheit - neben Technik und Organisation - das „elastische Potential“ von Arbeit (respektive Arbeitskraft) grundsätzlich eine wichtige Rolle spielt (vgl. Altmann u.a. 1978). Neu ist vielmehr, daß Unbestimmtheit nun vermehrt von den Beschäftigten selbst bewältigt werden soll. Der neue Rationalisierungsmodus setzt nicht mehr ,nur“ auf das elastische Potential, das dem qualifkatorischen und physischen Arbeitsvermögen prinzipiell inhärent ist, sondern zunehmend auch auf das elastische Potential, das der Person, dem Subjekt ,hinter der Arbeitskraft“ zu eigen ist: Die Fähigkeit - und Bereitschaft - zur Selbststeuerung der Verausgabung des Arbeitsvermögens, zur Selbstorganisation der Verfügbarkeit und Leistungserbringung, zur Selbstrationalisierung der Arbeit. Die subjektive Gestaltung der individuellen Verfügbarkeit (eben: ihrer Flexibilität) sowie die Selbst-Rationalisierung der Arbeitsverausgabung (und die Partizpation an der Selbst-Rationalisierung anderer im Rahmen von Arbeits- oder Projektgruppen) wird zur entscheidenden Voraussetzung für die Bewältigung kontingenter und variabler Anforderungen (vgl. auch Bechtle 1994). ${ }^{5}$

\section{Entgrenzung von Arbeit und Leben}

Gleichermaßen Voraussetzung wie Folge ist die Entgrenzung von Arbeit, d.h. die Freisetzung der Arbeitskräfte aus institutionellen und normativen Begrenzungen ihrer Verfügbarkeit und Leistungsbereitschaft. Damit wird zugleich das in den institutionellen und subjektiven Grenzziehungen regulierte Verhältnis von Arbeitswelt und Lebenswelt, von Arbeitskraft und Person mittelbar oder unmittelbar selbst zum Bezugspunkt der Rationalisierung.

5 Ähnlich auch Brose, der drei Tendenzen und Konzepte des Organisationswandels anführt, die zugleich Versuche sind, der wachsenden Kontingenz der Unternehmensumwelten durch Reorganisation beizukommen: „Dezentralisierung“, „Diskontinuitätsmanagement“ sowie „Delegation“, wobei letztere die „Sozialdimension“ umfasst und - unter Bezugnahme auf Voswinkel - als „Umstellung der Leistungssteuerung von Verfahrenskontrolle auf Ergebnisorientierung; Transformation von Arbeitsverträgen in Lieferverträge und Umstellung von Kooperations- auf Tauschbeziehungen“ fasst (Brose 2000, S. 22f.; vgl. auch Voswinkel 2000; Holtgrewe, Voswinkel 2002). 
Die These der Entgrenzung von Arbeit behauptet, daß nun jene Grenzziehungen erodieren, die für die betriebliche Organisation von Arbeit im Fordismus-Taylorismus in spezifischer Weise konstitutiv und strukturprägend waren: In der Dimension der Nutzung von Arbeitskraft, der Organisation, Steuerung und Kontrolle ihrer Verausgabung sind es vor allem die Grenzziehungen zwischen Objekt und Subjekt der Rationalisierung sowie zwischen Person und Arbeitskraft im Rahmen neuer Ansätze der Selbstorganisation von Arbeit. In der Dimension des Einsatzes, d.h. der Organisation der Verfügbarkeit von Arbeitskraft sind es insbesondere die arbeitskraftbezogenen Grenzziehungen zwischen „Innen“ und „Außen“ des Betriebs, zwischen internen und externen Arbeitsmärkten, zwischen Arbeitszeit und Freizeit, zwischen Arbeitsort und Wohnort, zwischen Arbeitswelt und Lebenswelt, die im Zuge der forcierten Flexibilisierung von Arbeit nun zur Disposition stehen.

Entgrenzungsprozesse, die in der Diskussion bislang die meiste Aufmerksamkeit erhalten haben, beziehen sich vor allem auf die Flexibilisierung von Beschäftigungsverhältnissen und Arbeitszeiten. Dies hat mehrere Gründe: Zum einen liegen sie im Brennpunkt betrieblicher Einsatz- und Nutzungsstrategien von Arbeitskraft, zum anderen sind sie zentrale Elemente einer früheren Dekommodifizierung von Arbeitskraft (vgl. Bosch 2001). Mit Dekommodifizierung ist ein historischer Prozeß gemeint, in dem durch Regulierung von Beschäftigung und Arbeitszeit anerkannt wird, daß die Arbeitskraft eine besondere Ware ist, die an den Menschen als natürliches und soziales Wesen gebunden ist und von daher auch besonderen Schutzes bedarf. Dies wird nun sukzessive zurückgenommen. Eine derartige Flexibilisierung von Arbeit und Leben verbindet sich deswegen mit einer Entsicherung nicht nur der Arbeits-, sondern auch der Lebensverhältnisse.

Die Tendenz einer zunehmenden Subjektivierung verändert nicht nur die Verhältnisse innerhalb der Arbeitswelt, sondern berührt ebenfalls das Verhältnis von Arbeit und Leben: Mit dem Bedeutungsgewinn subjektiver Handlungen und Deutungen im Arbeitsprozeß und den erweiterten subjektiven Ansprüchen an die Arbeit erhalten individuelle Ressourcen und Fähigkeiten einen neuen Stellenwert, die bisher dem heim- und familienbasierten privaten Leben zugerechnet und dort auch ausgebildet werden (kommunikative und interaktive Fähigkeiten, Selbstverantwortung, Gefühle u.ä.). Umgekehrt resultieren aus einer zunehmenden Verschränkung von Arbeit und Leben wachsende Anforderungen an aktive individuelle Gestaltungsleistungen (,strategische Lebensführung“, Selbstmanagement u.ä.). 


\section{Heterogenität und Ambivalenz}

Der Ansatz, zentrale Prozesse der gegenwärtigen Entwicklung von Arbeit unter zwei Begriffe zu fassen - Flexibilisierung und Subjektivierung - hat zum Ziel, in der Vielfalt und Dynamik von Veränderungsprozessen wesentliche Strukturierungsprinzipien auszumachen, die das qualitativ Neue in den Umbruchprozessen benennen. Empirisch wie theoretisch geht es um die Erfassung von Umbrüchen, d.h. um die Infragestellung und Auflösung einer relativ stabilen historischen Konstellation, wie sie der Fordismus darstellt. Es geht explizit nicht um den Versuch, das qualitativ Neue bereits als Element einer historisch neuen Konstellation, einer neuen historischen Formation oder auch nur eines neuen Produktionsmodells auszuweisen.

Die Pluralität und auch Widersprüchlichkeit der gegenwärtigen Positionen zum Umbruch von Arbeit ist nicht verwunderlich, da die gegenwärtige Entwicklung „für jeden etwas bereit hält““, tatsächlich gekennzeichnet ist von einem Nebeneinander von alten und neuen Merkmalen und von vorwärts und rückwärts gewandten Tendenzen. Veränderungen setzen sich sehr ungleichzeitig in unterschiedlichen gesellschaftlichen Bereichen durch, und ihre Konsequenzen erweisen sich als sehr zwiespältig für die Betroffenen. Offensichtlich sind Heterogenität und Ambivalenz die entscheidenden abstrakten Merkmale der gegenwärtigen Umbruchprozesse.

In dieser Sichtweise wäre die Behauptung, der Taylorismus würde der Vergangenheit angehören, falsch. Neben den neuen Organisationsformen der gesellschaftlichen Produktion bestehen

alte Formen fort und werden z. T. sogar noch verschärft. ${ }^{6}$ Dennoch zeigt sich selbst da, wo fordistische Organisations- und Arbeitsformen fortbestehen oder in neo-tayloristischer Art neu entstehen, daß Veränderungstendenzen greifen, in die einzelne Elemente einer Flexibilisierung und Subjektivierung eingelagert sind (vgl. z.B. die Analysen zur „flexiblen Standardisierung“ in der Automobilindustrie, Springer 1999). Und dort, wo weiterreichende Umstrukturierungen stattgefunden haben, Unternehmen sich weitgehend dezentralisiert und vermarktlicht haben, die Arbeitsorganisation flexible Züge trägt und die Arbeit selbst hohe Autonomie erhält, bleiben Formen zentralistischer Koordination erhalten, werden Standardisierungsprozesse weitergetrieben, verbinden sich subjektivierte Arbeitsformen mit neuen Formen einer objektivierten Steuerung (vgl. zur Analyse der in den letzten Jahren entwickelten Formen eilierte Arbeitsformen in der Produktion fortbestehen (vgl. u.a. Kurz 1998) und vor allem im Dienstleistungssektor (Handel, Banken, Versicherungen) zunehmen. 
ner indirekten Steuerung, Glißmann, Peters 2001). Und auch die Prozesse einer Autonomisierung in der betrieblichen Organisation von Arbeitsprozessen (erweiterte Spielräume) und die komplementär dazu wachsende Subjektivierung der Arbeitstätigkeiten (erweiterter Einsatz subjektiver Potentiale und Leistungen) erweisen sich als paradoxer Prozeß mit höchst ambivalenten Folgen: für die Arbeitskräfte, deren Subjektivierung eine ungeahnte Instrumentalisierung ihrer Subjektivität ermöglicht und für die Betriebe, die z. B. nicht zugleich den Intrapreneur bzw. den „flexiblen Menschen“ und den „loyalen Mitarbeiter“ haben können (vgl. Moldaschl, Voß 2002, S. 15).

Selten war so viel von Ambivalenzen und Paradoxien die Rede, wie in den Diagnosen und Debatten, die sich in einer begrifflichen Fassung moderner Arbeits- und Beschäftigungsformen versuchen: So wurde mit dem Label einer „kontrollierten Autonomie“ oder einer „Kontrolle durch Autonomie“ sowohl das Verhältnis von Markt und Hierarchie, von Abhängigkeit und Eigenständigkeit in neuen Formen inner- und zwischenbetrieblicher Kooperationsbeziehungen, wie auch das Verhältnis von Kooperation und Herrschaft in allen Arbeitszusammenhängen zu bestimmen versucht (vgl. Vieth 1995; Kühl 1994; Sauer, Döhl 1994; Wolf 1999; Moldaschl 1994; Moldaschl, Sauer 2000 u.a.). Auch die These von einem neuem Typus von Arbeitskraft, des „Arbeitskraftunternehmers“ (Voß, Pongratz 1998) zeichnet sich in seiner betrieblichen Stellung durch fremdorganisierte „Selbstorganisation“ aus, und mit der Figur des „unselbständig Selbständigen“ wird von Glißmann und Peters die neue Autonomie in der Arbeit mit ihren paradoxen Folgen (,mehr Druck durch mehr Freiheit“) plakativ auf den Punkt gebracht (vgl. Glißmann, Peters 2001).

\subsection{Ansatz der Berichterstattung}

Die Zielsetzung des Themenfeldes besteht darin, ausgehend von neueren Entwicklungen der Unternehmensorganisation und der betrieblichen Organisation von Arbeit einen zentralen Teilbereich gesellschaftlichen Wandels auszuleuchten. Konstitutiv ist zum einen eine doppelte methodische Perspektive, d.h. eine Berichterstattung, die sowohl auf der betrieblichen als auch auf der individuellen Ebene ansetzt. Zum anderen läßt sich die Frage eines „Umbruchs“ nicht isoliert anhand eines Themenfeldes oder Berichtsgegenstandes betrachten. So wie die fordistisch-tayloristische Organisation von Unternehmen und Arbeit in ihrer „epochemachenden“ Gestalt auf kohärente institutionelle Arrangements verweist, in denen die Beziehungen zwischen Makro, Meso- und Mikroebene spezifische ,positive Rückkoppelungen“ aufweisen (Bechtle, Lutz 1989), so ist die Krise einer solchen Formation, ihr Umbruch, 
nicht alleine vor dem Hintergrund eines gesellschaftlichen Feld - so zentral es auch immer sein mag - deutbar.

Im Mittelpunkt des Themenfeldes stehen daher Prozesse der Flexibilisierung und Subjektivierung von Arbeit, die sowohl als betriebliche Strategien und Politiken als auch auf der individuellen Ebene erfaßbar sein müßten. Sowohl die doppelte Perspektive auf Betrieb und Individuum wie auch die These von der Erosion institutioneller und normativer Grenzen der Verfügbarkeit und Leistungsbereitschaft von Arbeitskräften mündet in ein Berichtskonzept, das soweit möglich - sowohl die objektiven wie auch die subjektiven Bedingungen und Folgen von Prozessen der Flexibilisierung und Subjektivierung beachten muß:

\begin{tabular}{|c|c|c|}
\hline & Betriebliche Ebene & Individuelle Ebene \\
\hline Objektiv & $\begin{array}{ll}\text { - } & \text { Beschäftigungsstrategien } \\
\text { - } & \text { Arbeitszeitorganisation } \\
\text { - } & \text { Neue Arbeitsformen (z.B. Pro- } \\
& \text { jekt- oder Gruppenarbeit) } \\
\text { - } & \text { Neue Formen der Leistungspolitik } \\
\text { - } & \text { Differenzierung nach Betriebsty- } \\
& \text { pen }\end{array}$ & $\begin{array}{ll}- & \text { Beschäftigungsverhältnisse, Arbeits- } \\
& \text { zeiten und Arbeitsformen verschie- } \\
& \text { dener Arbeitskräftegruppen (Diffe- } \\
\text { renzierung nach Alter, Geschlecht, } \\
\text { Qualifikation etc.) } \\
\text { - } & \text { Differenzierung nach Familienfor- } \\
\text { men und Haushaltstypen } \\
\text { - } & \text { Regionale Differnzierung (Ost/West) }\end{array}$ \\
\hline Subjektiv & $\begin{array}{ll}- & \text { Arbeitsformen der Selbstorgani- } \\
& \text { sation (von Arbeit und Arbeitsein- } \\
\text { satz) } \\
\text { - } & \text { Individualisierung des Arbeitsein- } \\
& \text { satzes } \\
\text { - } & \text { Formen diskursiver Rationalisie- } \\
& \text { rung } \\
\text { - } & \text { Individuenzentrierte Personalent- } \\
& \text { wicklung } \\
\text { - } & \text { Qualifizierung „weicher“ Kom- } \\
\text { petenzen }\end{array}$ & $\begin{array}{ll}- & \text { Arbeits- und Erwerbsorientierungen } \\
- & \text { Subjektive Bedürfnisse und Ansprü- } \\
& \text { che } \\
- & \text { Wahrnehmung und Bewertung flexi- } \\
& \text { bilisierter und subjektivierter Arbeit } \\
- & \text { Gestaltung des Verhältnisses von } \\
& \text { Arbeit und Leben }\end{array}$ \\
\hline
\end{tabular}

Im Themenfeld werden Prozesse der Flexibilisierung und Subjektivierung in drei Dimensionen untersucht: Der Flexibilisierung der Beschäftigungsverhältnisse, der Flexibilisierung von Arbeitszeiten sowie der Subjektivierung von Arbeit. 
Quer zur Differenzierung in Prozesse der Flexibilisierung und Subjektivierung liegt ein Spannungsfeld, das aus der (vermutlich wachsenden) Heterogenität resultiert. Die wachsende Differenzierung von Erwerbsarbeit - und ebenso die Differenzierung sozialer Lagen, Lebensstile und Lebensläufe - setzt generalisierende Aussagen prinzipiell der Gefahr der unzulässigen Verallgemeinerung aus. ${ }^{7}$ Das Gegenteil - die Kapitulation vor der „Unübersichtlichkeit“ wäre jedoch ebenso vorschnell. Gewissermaßen als ein dritter Weg könnte es gerade darum gehen, den gegenwärtigen Umbruch als einen Anpassungs- oder Übergangsprozeß zu identifizieren, in dem das „Neue“ gerade in einer wachsenden, aber systematisch verknüpften und strukturell begründbaren Heterogenität besteht (vgl. Bechtle, Sauer 2001/02; Röttger 2001/02). Auf, allerdings abstraktem, Niveau besteht das (Fern-)Ziel dann genau darin, in den heterogenen Strukturen gewissermaßen Heterogentität als Prinzip zu erkennen. Das Themenfeld versucht mit seiner Konzeption einen Schritt in diese Richtung zu gehen: Indem gerade Prozesse der Flexibilisierung und der Subjektivierung in den Blick genommen werden, werden nicht nur zwei zunächst unterschiedliche Entwicklungstendenzen von Arbeit (und mögliche Umbruchindikatoren) zentral gestellt, sondern auch wesentliche Momente der Heterogenität von Arbeit erfassbar: Beide Prozesse weisen - in der Diskussion - negative wie positive Pole auf, die jeweils sehr unterschiedlichen Beschäftigtengruppen zugeordnet werden (können). So ist bei der Thematisierung von Flexibilisierungsprozessen einerseits von der Prekarität der modernen Tagelöhner und der Menschen in weitgehend ungeschützten Beschäftigungsverhältnissen die Rede, andererseits von der zeitlichen, räumlichen und beruflichen Flexibilität der „High Potentials“. Der Subjektivierungsdiskurs fokussiert von vornherein vor allem auf diese Gruppe und macht das jeweils negative und positive Ende in der Ambivalenz subjektivierter Arbeit fest (programmatisch: Moldaschl, Voß 2002).

Die nachfolgenden Abschnitte zu empirischen Befunden der Flexibilisierung und Subjektivierung von Arbeit sind in unterschiedlicher Weise ausgearbeitet. Dies korrespondiert mit der jeweiligen Ausrichtung und dem Bearbeitungsstand der zugrundeliegenden Berichtsgegenstände. Die Ausführungen zur Flexibilisierung der Beschäftigungsverhältnisse beziehen sich insbesondere auf das Material, das in den Berichtsgegenständen „Unternehmens- und Arbeitsorganisation“ sowie „Beschäftigungsverhältnisse“ aufbereitet wurde. Allerdings war es hier notwendig, auch andere Daten und Quellen einzubeziehen, da der erstgenannte Berichts- 
gegenstand vornehmlich die betriebliche Ebene und der zweitgenannte die generelle Entwicklung der Beschäftigungsverhältnisse, jedoch nur teilweise unmittelbar Tendenzen der Flexibilisierung fokussiert. Der Abschnitt zur Flexibilisierung der Arbeitszeit verzichtet demgegenüber weitgehend auf die Präsentation von Daten und stellt stattdessen insbesondere neuer Entwicklungen der Arbeitszeitorganisation in den Mittelpunkt, die sich unmittelbar mit Prozessen einer Flexibilisierung und Selbstorganisation von Arbeitszeit verbinden und fragt hier gezielter nach den subjektiven Konsequenzen. Der Abschnitt zur Subjektivierung von Arbeit kann dagegen nur begrenzt auf bereits in Berichtsgegenständen vorgenommene Analysen zurückgreifen (in Teilen gilt dies für den Berichtsgegenstand „Unternehmens- und Arbeitsorganisation"), so daß hier ebenfalls etwas umfangreicher auch empirische Daten und Befunde dargestellt werden müssen.

\section{Flexibilisierung der Beschäftigung}

\subsection{Thesen und Ansatz}

\section{Fragestellung und Thesen}

Das Thema der Flexibilisierung von Beschäftigungsverhältnissen läßt sich nicht ohne die seit Jahren anhaltende Debatte über die „Erosion des Normalarbeitsverhältnisses“ diskutieren (vgl. Mückenberger 1985; Osterland 1990; Matthies u.a. 1994; Zukunftskommission 1996; Bosch 2001). In der wissenschaftlichen Diskussion gilt - pointiert artikuliert durch die bayerisch-sächsische „Kommission für Zukunftsfragen“ - als Konsens, daß Zahl und/oder Anteil der „Normalarbeitsverhältnisse“, also der unbefristeten Vollzeit-Arbeitsverhältnisse mehr oder weniger kontinuierlich zurückgehen und möglicherweise in absehbarer Zukunft nicht mehr die dominante Erwerbsform darstellen werden. Trotz dieser scheinbaren Eindeutigkeit, die nicht zuletzt ihrer gebetsmühlenartigen Widerholung geschuldet ist, regte sich Kritik an der These einer breiten Erosion des Normalarbeitsverhältnisses. So wurde etwa die Validität des empirischen Datenmaterials kritisiert, auf dessen Basis die bayerisch-sächsische Zukunftskommission Mitte der 90er Jahre zu dem Schluß kam, daß sich eine ,zunehmende Ersetzung von Norm- durch Nicht-Normarbeitsverhältnisse“ beobachten läßt und das bei „Fortschreibung dieses Trends das Verhältnis von Norm- und Nicht-Normarbeitsverhältnissen in fünfzehn Jahren bei eins zu eins liegen wird“ (Zukunftskommission 1996, S. 62; vgl. zur Kritik Senatsverwaltung 1998). In dieser Diskussion, die sich vornehmlich um den empirischen Beweis der Flexibilisierungstendenz rankte, wurden vor allem zwei Dinge deutlich: Erstens 
gibt es erhebliche Unterschiede, je nachdem, was als „Normalarbeitsverhältnis“ und was als „atypisch“, als davon abweichend, definiert wird. ${ }^{8}$ Und zweitens wurde deutlich, daß generell die (quantitative) Datenbasis zur Erfassung insbesondere neuer, vom Normarbeitsverhältnis abweichender Erwerbsformen, zumindest lückenhaft und unsicher ist (vgl. Kratzer u.a. 1998). Und drittens ist der methodische Zugang entscheidend: „Daß das NAV (Normalarbeitsverhältnis, Anm.) tatsächlich an Boden verloren hat, gehört zu den fast selbstverständlichen Grundannahmen der heutigen Debatte. Schauen wir nur auf die quantitative Entwicklung, ergibt sich ein ziemlich unterschiedliches Bild, je nachdem ob man auf absolute oder relative Zahlen, Arbeitszeiten oder die Stabilität der Beschäftigungsverhältnisse schaut", so etwa Bosch (Bosch 2001, S. 221; vgl. auch Bosch u.a. 2001; Erlinghagen, Knuth 2002). ${ }^{9}$ Hinzuzufügen wäre, daß ebenso wichtig ist, welche Datenbasis man wählt (vgl. Deml, Struck-Möbeck 1998).

Allen kritischen Aspekten zum Trotz, läßt sich jedoch - und hierin besteht im Grunde dann auch Übereinstimmung - feststellen, daß sich mit offensichtlich anhaltender Tendenz die Beschäftigungsstrukturen ausdifferenzieren und pluralisieren (siehe Klammer, Tillmann 2001). In der Folge kommt es $\mathrm{zu}$ einem relativen Rückgang von unbefristeten VollzeitBeschäftigungsverhältnissen, d. h. in diesem Sinne von „Normalarbeitsverhältnissen“. Relativer Rückgang bedeutet, daß der Anteil von Normalarbeitsverhältnissen an allen Erwerbsformen abnimmt und das zugleich die Anteile von Erwerbsformen jenseits des Normalarbeitsverhältnisses zunehmen. Die Ursache dieser Entwicklung sind insgesamt zwischen Mitte der 80er Jahre und dem Ende der 90er Jahre praktisch stagnierende absolute Zahlen von Normalarbeitsverhältnissen und eine Zunahme der Gesamtzahl der Erwerbstätigen, die überproportional auf das Konto von Nicht-Normalarbeitsverhältnissen geht. Die Erosion des Normalar-

Wesentliche Unterschiede existieren hier bei der Frage, ob nun Teilzeitbeschäftigungsverhältnisse als „normal“ anzusehen sind oder nicht, wie sich das mit befristeten Beschäftigungsverhältnissen verhält - vor allem angesichts theoretisch möglicher und real praktizierter Befristungsdauern von bis zu zwei Jahren und inwiefern nicht nur die Dauer der Arbeitszeit, sondern auch deren Lage und Verteilung auf den Tag oder die Woche ein entscheidendes Kriterium sein sollte. Je nachdem verschieben sich die Anteile in z.T. erheblichem Ausmaß (vor allem durch Hinzunahme von Teilzeitbeschäftigten und denjenigen mit regelmäßiger Schicht-, Nacht- oder Wochenendarbeit) (vgl. Bosch u.a. 2001; Klammer, Tillmann 2001).

Kritik wurde darüber hinaus an der vermeintlichen „Säkularität“ der Flexibilisierungstendenz geübt. In vielen einschlägigen Publikationen wird der Trend hin zu flexibleren Beschäftigungsverhältnissen implizit als mehr oder weniger unumkehrbar, als geradezu säkularer Trend dargestellt. Demgegenüber verweisen etwa Bosch oder auch Hoffmann und Walwei darauf, das solche Entwicklungstendenzen nicht nur Ergebnis politischer Gestaltung, sondern auch prinzipiell gestaltbar und damit auch reversibel sind (vgl. Hoffmann, Walwei 1998). 
beitsverhältnisses ist dann vor allem ein Prozeß der Differenzierung und Pluralisierung der Erwerbsformen (vgl. Klammer, Tillmann 2001), der vornehmlich den wachsenden Anteilen von Erwerbsformen jenseits des „Normalarbeitsverhältnisses“ zuzuschreiben ist.

Neben der - wie gesehen strittigen - quantitativen Entwicklung gibt es weitere Begründungen für die These einer zunehmenden Flexibilisierung der Beschäftigung, so u.a.:

Qualitative Studien zeigen, daß die Unternehmen vergleichsweise große und - und das ist noch wichtiger - wachsende Anteile von „Mitarbeitern“ aufweisen, die dem flexiblen Beschäftigungssegment zuzuordnen sind: $\mathrm{Ob}$ das der selbständige Kantinenpächter, „externe“ Programmierer oder Leiharbeitnehmer in der Produktion sind, viele Tätigkeiten und Funktionen, die früher selbstverständlich von festangestellten Mitarbeitern ausgeübt wurden, werden heute - und genauso selbstverständlich - von „Externen“ oder „Flexiblen“ ausgeführt (vgl. Kratzer, Döhl 2000; Dörre 2001; Kratzer 2002).

(2) Von steigenden Flexibilitätsanforderungen an die Unternehmen einerseits und einem wachsenden Kosten- und Konkurrenzdruck andererseits dürfte ein zunehmender Druck auf den „Kostenfaktor Personal“ ausgehen: Eine Folge ist, daß sich der Personalbestand tendenziell an der unteren Kapazitätsauslastung orientiert. Wenn unter der Bedingung knapper Personalressourcen Auslastungsschwankungen nicht mehr über die Flexibilisierung der Arbeitszeiten bewältigt werden können oder dynamisch veränderliche arbeitsinhaltliche Anforderungen mit spezifischen Qualifikationsbedarfen einhergehen, müssen Unternehmen diese Anforderungen zunehmend über den - zeitlich begrenzten oder dauerhaften - Einsatz flexibel Beschäftigter bewältigen.

(3) Vor allem in größeren Unternehmen wird seit längerem ein Prozeß der Dezentralisierung und oft damit verbunden auch der wachsenden Kosten- oder Erlösverantwortlichkeit der dezentralen Unternehmenseinheiten beobachten. Damit fallen dann zunehmend die personellen „Puffer“ großer Organisationen weg. Überspitzt ausgedrückt verwandeln sich Großbetriebe nach und nach in zentral gesteuerte und marktlich koordinierte Netzwerke von „SemiKleinbetrieben“, die dann ihrerseits unmittelbarer einem wachsenden Kostendruck ausgesetzt sind.

(4) Die Unternehmenslandschaft insgesamt unterliegt sowohl einer Tertiarisierungs- als auch einer Verkleinbetrieblichungstendenz (vgl. dazu auch den Berichtsgegenstand „Unternehmens- und Arbeitsorganisation"). Mit beiden Prozessen verbinden sich aber bekanntermaßen 
eine tendenziell unsicherere Beschäftigungslagen bzw. eine höhere Fluktuation (dies sind vor allem Merkmale des kleinbetrieblichen Segments) sowie ein größerer Anteil ,atypischer Beschäftigung“ (dies gilt als Merkmal vieler Dienstleistungsbranchen). Mit einem Wandel der Unternehmensstrukturen in Richtung Dienstleistungs- und Kleinbetriebe würden sich dann jedoch auch die spezifischen Merkmale ausweiten.

(5) Eine weiterer Push in Richtung Flexibilisierung könnte jedoch auch aus veränderten Erwerbsorientierungen resultieren: Angesichts der Ausdifferenzierung und Individualisierung von Lebens- und Erwerbsentwürfen steigt auch bei den Beschäftigten zumindest die Akzeptanz neuer Erwerbsformen (vgl. Baethge 1991; Trautwein-Kalms 1995; Haak, Schmid 2001; Frick u.a. 1999). Dabei dürfte nicht immer leicht zu klären sein, inwieweit die Akzeptanz flexibler Erwerbsformen gewissermaßen negativ motiviert ist, sich angesichts persistenter Arbeitslosigkeit vor allem in der Einsicht in die Notwendigkeit gründet (z.B. „Selbständigkeit als Reflex auf Arbeitslosigkeit“, vgl. Bögenhold, Staber 1990) oder auf alternativen Lebensentwürfen, subjektiven Berufsperspektiven etc. beruht, in diesem Sinne also positiv konnotiert wird und damit nicht bloß Akzeptanz, sondern eben u.U. auch Ausdruck von Forderungen oder Wünschen der Beschäftigten selbst ist. ${ }^{10}$

Häufig wird Flexibilisierung als etwas an sich „Neues“, geradezu als Signum moderner Arbeits- und Beschäftigungsorganisation dargestellt und implizit unterstellt, daß das fordistischtayloristische Produktionsmodell demgegenüber unflexibel, vergleichsweise starr gewesen sei. Bei näherem Hinsehen wird dann jedoch schnell klar, daß die fordistisch-tayloristische Beschäftigungsorganisation keineswegs so unflexibel war, wie es in machen Publikationen dargestellt wird: Wohl immer schon mußten Unternehmen auf veränderte und veränderliche Umweltbedingungen reagieren und sie haben dabei - neben anderem - immer auch flexibel auf externe Arbeitskräfte zurückgegriffen (vgl. Sengenberger 1987; Lutz 1987; Schienstock 1998).

Ein zentrales Element des fordistisch-tayloristischen Flexibilisierungsmodus ist die Segmentation der betrieblichen Arbeitsmärkte in Stamm- oder Kernbelegschaften und Randbelegschaften und die hier jeweils unterschiedlichen Flexibilisierungsstrategien: Die qualifizierte

Eine repräsentative Befragung des Forschungsinstituts für Ordnungspolitik kommt hier eher zu einem ambivalenten Ergebnis: Zwar verbinden sich mit dem Begriff der „Flexibilisierung“ überwiegend positive Assoziationen, insgesamt scheint aber eher „Einsicht in die Notwendigkeit“ und begrenzte Flexibilisierungsbereitschaft vorherrschend zu sein. Im Gegenzug wird die eminente Bedeutung von „Sicherheit“ hervorgehoben (vgl. Föste u.a. 2001). 
Kernbelegschaft steht idealtypisch für die „funktionale“ Flexibilität, d.h. die vor allem arbeitsinhaltliche Anpassung an wechselnde Erfordernisse und Qualifikationsanforderungen; die - un- oder angelernte - Randbelegschaft ist dagegen wesentliches Instrument zur Erhöhung der „numerischen“ Flexibilität, d.h. zur flexiblen Anpassung des Personalbestandes insbesondere an Konjunktur- oder Auftragsschwankungen (vgl. Atkinson 1984; Sengenberger 1987; Köhler, Preißendörfer 1989). Während - wiederum idealtypisch - die wechselseitige Bindung von Betrieb und Beschäftigten im Falle der Kernbelegschaften hoch ist - und durch eine Reihe von institutionellen Regelungen auch hoch gehalten wird (etwa Senioritätsrechte) - , sind die Randbelegschaften vor allem quantitativer Puffer für standardisierte Tätigkeiten und mit entsprechenden Beschäftigungsrisiken konfrontiert. Weitere Elemente sind die Ausweitung der Betriebszeiten durch Schicht-, Nacht- oder Wochenendarbeit sowie - in der Regel angeordnete - Überstunden (vgl. Bosch 2001).

Damit steht die Frage nach einem gegenwärtig stattfindenden Formwandel der Flexibilisierung im Raum, von dem sich sprechen läßt, wenn die gegenwärtig beobachtbaren Tendenzen einer Flexibilisierung nicht nur quantitativ bedeutsamer werden, sondern sich auch qualitativ, in Logik und Form vom fordistisch-tayloristischen Modell unterscheiden. Kurz: Das „Neue“ an der Flexibilisierung wäre dann nicht die Flexibilisierung an sich, sondern ein neuer Modus der Flexibilisierung; das Neue am Prozeß der Flexibilisierung ist dementsprechend ebenfalls nicht die Flexibilisierung als solche, sondern der Formwandel der Flexibilisierung:

Die zunehmende Dezentralisierung und Desintegration von Wertschöpfungsprozessen läßt eine virtuelle Gesamtbelegschaft entstehen. Diese ist Gesamtbelegschaft, da sie in ihren ausdifferenzierten Funktionen dennoch auf einen Produkt- oder Dienstleitungszusammenhang bezogen bleibt und sie ist virtuell, da sie räumlich und funktional desintegriert ist. Auf der Ebene des einzelnen Betriebes kommt es ebenfalls zu einer Virtualisierung der (betrieblichen) Belegschaft: Virtualisierung meint hier primär die Zunahme flexibler Beschäftigung. Die Virtualisierung der Belegschaft stellt auf jeder der beiden Ebenen einen tendenziellen Bruch mit fordistisch-tayloristischen Flexibilisierungsmustern dar: Auf der Ebene der Organisation werden Flexibilitätserfordernisse nunmehr weniger durch interne Flexibilität, durch die Puffer, die die Organisation selbst bereithält, ausgeglichen; vielmehr werden die mit wachsenden und unterschiedlichen Flexibilitätserfordernissen verbundenen Problemstellungen zunehmend externalisiert und durch weitergehende Segmentation „gelöst“. Auf der betrieblichen Eben ist die ,atmende“ Fabrik (Hartz 1996) das konzeptionelle Leitbild. Diese stellt insofern einen Bruch mit dem traditionellen Model der „flexible firm“ (Atkinson 1984; vgl. auch Schienstock 1998, S. 164f.) dar, als zum einen auch die Kernbelegschaft vor allem über die anforderungsgerechte Anpassung der Arbeitszeit in deutlich höherem Maße flexibilisiert wird und zum anderen auch vormals als „Kern“ definierte Funktionen zunehmend von Externen ausgefüllt werden. Die „Virtualisierung“ der Belegschaft ist in dieser Perspektive die strategisch 
genutzte Erosion der Grenzen zwischen Betrieb und Arbeitsmarkt und der tendenziellen Verschränkung interner und externer Arbeitsmärkte.

Damit ist unmittelbar eine Tendenz der wachsenden Heterogenität des flexiblen Beschäftigungssegments verknüpft. In dem Maße wie auch ehemalige Kernfunktionen zunehmend von externen Arbeitskräften besetzt werden, wandelt sich auch die Zusammensetzung des flexiblen Beschäftigungssegments. Dieses ist nicht länger überwiegend als „Jedermannsarbeitsmarkt“ (vgl. Lutz 1987; Sengenberger 1987), als „Domäne“ vorrangig un- oder angelernter Arbeitskräfte zu begreifen, deren Funktion in der Abpufferung von quantitativen Flexibilitätsanforderungen bzw. Marktschwankungen liegt und deren Einsatzfelder vor allem standardisierte, intersubjektiv austauschbare Tätigkeiten sind. Vielmehr finden sich hier neben den „Jedermannsarbeitskräften“ zunehmend auch Qualifizierte und Hochqualifizierte sowie ein breiteres Spektrum an „nicht-normalen“ Erwerbsformen (Freiberufler, Selbständige, befristet Beschäftigte, geringfügig Beschäftigte, Leiharbeitnehmer u.a.) (vgl. Schreyer 2000). Hier findet sich dementsprechend auch ein zunehmend heterogeneres Sample individueller Gründe bzw. Ursachen (polar: „Ökonomie der Not“ vs. „Ökonomie der Selbstverwirklichung“, vgl. dazu Bögenhold, Staber 1990) sowie unterschiedlicher Arbeits- und Beschäftigungsbedingungen (vom selbständigen Berater mit weitgehender Autonomie und üppigen Honoraren bis zur geringfügig beschäftigten Produktionsaushilfe).

Das Neue an der Flexibilisierung ist somit - so die These - zum einen die wachsende Verbreitung flexibler Beschäftigungs- bzw. Erwerbsformen, ihre relativ steigende Bedeutung in der Erwerbsstruktur sowie die normative Konkurrenz und In-Fragestellung, die das „Normalarbeitsverhältnis“ durch diese Entwicklung erhält. Die Flexibilisierung der Beschäftigung ist zum anderen aber auch insofern etwas „Neues“, als sie gerade mit neuen Organisationsstrukturen erst ihre Dynamik und Virulenz zu erhalten scheint. Anders gesagt: Manche Aspekte des seit längerem beobachtbaren Flexibilisierungsgeschehens sind gewissermaßen eine Nebenfolge (genauso aber auch Voraussetzung) neuartiger Reorganisationsstrategien und erhalten erst mit der Durchsetzung solcher Strategien ihre weiterreichende Dynamik (vgl. dazu auch Kratzer, Döhl 2000). Ebenfalls „Neues“ läßt sich hinsichtlich der Flexibilisierungsmodi erkennen: Der „alte“ Modus der Segmentation in Kern- und Randbelegschaften und der Nutzung der hier jeweils spezifischen Flexibilitätspotentiale kann u.U. nicht länger als generelles Prinzip gelten. Mehr und mehr erreicht die Flexibilisierung der Beschäftigung auch die ehemaligen Kernfunktionen eines Unternehmens und - eng damit verbunden - auch 
die Qualifizierten und Hochqualifizierten. Diese Entwicklung kommt vor allem in der wachsenden Heterogenität des flexiblen Beschäftigungssegments zum Ausdruck.

\section{Ansatz}

Diese Teilfragestellung des Themenfeldes setzt daher eine (Daten-)Anlayse sowohl auf der betrieblichen wie auf der individuellen Ebene voraus.

Auf der betrieblichen Ebene geht es dabei um:

- den Zusammenhang von betrieblichen Restrukturierungstendenzen sowie der Veränderung der Unternehmensstruktur und den damit verbundenen Beschäftigungseffekten. Beschäftigungseffekte können hinsichtlich der Größe bzw. der Entwicklung der Belegschaft sowie der Struktur der Belegschaft im Hinblick auf Arbeitskräfte- bzw. Qualifikationsgruppen und Erwerbsformen vermutet werden.

- den Zusammenhang von spezifischen betrieblichen Merkmalen und des jeweiligen Anteils von „normalen“" und „flexiblen“ Beschäftigten“.

Auf der individuellen Ebene geht es um:

- die Entwicklung der Erwerbsformen und der

- Struktur von jeweils spezifischen Erwerbsformen (d.h. die Differenzierung einzelner Erwerbsformen etwa nach Qualifikation, Alter und Geschlecht der Erwerbstätigen).

Die nachstehenden Ausführungen stützen sich insbesondere auf die Befunde der Berichtsgegenstände „Unternehmens- und Arbeitsorganisation“ sowie „Beschäftigungsverhältnisse“, beziehen darüber hinaus jedoch andere (quantitative wie qualitative) Untersuchungen (bzw. deren Ergebnisse) ein.

\subsection{Empirische Befunde zur Flexibilisierung der Beschäftigung}

\section{Entwicklung und Struktur flexibler Beschäftigung auf der betrieblichen Ebene}

Zwischen einzelnen Branchen und Betriebsgrößenklassen bestehen teilweise erhebliche Unterschiede im Anteil „flexibel Beschäftigter": Im Jahr 2001 sind in Westdeutschland rund ein Viertel der Beschäftigten in Unternehmen der privaten und öffentlichen Dienstleistungen Teilzeitbeschäftigte (hier wurden nur diejenigen Teilzeitbeschäftigten gezählt, deren wöchentliche Arbeitszeit unter 24 Stunden liegt), befristet angestellt, Leiharbeitnehmer bzw. 
Aushilfen, freie Mitarbeiter, geringfügig Beschäftigte u.ä. (letztere drei Gruppen werden im Betriebspanel des IAB als „sonstige Beschäftigte“ erfasst). Ähnlich hohe Werte weise sonst nur noch Betriebe der Land- oder Forstwirtschaft auf, wobei hier vor allem die saisonale Beschäftigung durchschlagen dürfte. Für Ostdeutschland gilt in der Tendenz die gleiche Verteilung, wobei hier die jeweiligen Anteile geringer sind. Hinsichtlich der Betriebsgrößen läßt sich für Westdeutschland eindeutig feststellen, daß mit zunehmender Betriebsgröße der Anteil des „flexiblen Beschäftigungssegments“ abnimmt (in Kleinstbetrieben mit 1 bis 5 Beschäftigten sind es im Jahr 2001 rund 30\%, in Betrieben mit 1000 und mehr Beschäftigten dagegen „nur“ 16\%). Für ostdeutsche Betriebe läßt sich dagegen nur begrenzt von einem Betriebgrößeneffekt sprechen, da die Unterschiede hier vergleichsweise gering sind und eine ähnliche Tendenz nicht feststellbar ist.

Zwar läßt sich mit den bislang im Rahmen der Berichterstattung ausgewerteten Daten des IAB-Betriebspanels über die Entwicklung des flexiblen Beschäftigungssegments nur wenig Gesichertes aussagen (dies bleibt u.a. der geplanten Analyse von „Veränderungsraten“ im Längsschnitt vorbehalten), vorläufige Antworten für die Frage nach der bisherigen und weiteren Entwicklung lassen sich jedoch auch auf dieser Basis geben: Die Befunde der Berichtsgegenstände „Unternehmens- und Arbeitsorganisation“ sowie „Beschäftigungsverhältnisse“ bestätigen sowohl die Tendenz wachsender Anteile von Dienstleistungsunternehmen („Tertiarisierung") sowie eines zunehmenden Anteils von kleineren Betrieben an der Unternehmensstruktur. Beide Tendenzen könnten insofern auch in eine weitergehende Flexibilisierung der Beschäftigung münden als es gerade Kleinst- und Kleinbetriebe sowie Unternehmen der privaten und öffentlichen Dienstleistungen sind, die die größten Anteile „flexibel Beschäftigter“ aufweisen (vgl. dazu den Berichtsgegenstand „Unternehmens- und Arbeitsorganisation“). Und sieht man sich an, welche Branchen in den 90er Jahren durch Beschäftigungsgewinne oder-verluste gekennzeichnet waren, dann erweist sich auch hier, daß die zehn Branchen mit den stärksten Beschäftigungsgewinnen ausnahmslos Dienstleistungsbranchen sind und daß hier die sozialversicherungspflichtige Vollzeitbeschäftigung unterproportional wächst, wohingegen andere Beschäftigungsformen - allen voran die Teilzeitbeschäftigung - einen überproportionalen Anteil am Beschäftigungswachstum haben (vgl. dazu den Berichtsgegenstand „Beschäftigungsverhältnisse“).

\section{Entwicklung und Struktur der Erwerbstätigkeit}




\section{Entwicklung der Erwerbstätigkeit insgesamt}

Die Zahl der Erwerbstätigen ist seit 1960 zunächst mehr oder weniger kontinuierlich angestiegen: In Westdeutschland steigt die Zahl der abhängigen Erwerbspersonen von insgesamt etwas mehr als 20 Mio. im Jahr 1960 auf 25,5 Mio. im Jahr 1990. Zu Beginn der 90er Jahre beträgt die Zahl der abhängigen Erwerbspersonen im vereinigten Deutschland dann gut 33 Mio. Die 90er Jahre sind dann zunächst von einem Rückgang der Beschäftigung auf etwas mehr als 32 Mio. gekennzeichnet, bis nach einem Anstieg im Jahr 1999 wieder knapp 33 Mio. erreicht sind. Insgesamt geht dieser Anstieg vor allem auf eine steigende Erwerbsbeteiligung von Frauen zurück: Deren Anteil nimmt um 145\% zu (zu großen Teilen als Teilzeitbeschäftigung), während die Zahl erwerbstätiger Männer nur um rund 35\% zulegt. Vergleicht man die Entwicklung der sozialversicherungspflichtigen Beschäftigung mit der Entwicklung der (abhängigen) Erwerbstätigkeit insgesamt, dann ist das Wachstum nicht-sozialversicherungspflichtiger abhängiger Beschäftigung höher als das der sozialversicherungspflichtigen Beschäftigung: Waren 1974 1,64 Mio. Männer und 0,5 Mio. Frauen nicht-sozialversicherungspflichtig beschäftigt, gibt es 1990 1,8 Mio. Männer und 1,16 Mio. Frauen in solchen Beschäftigungsverhältnissen (vgl. zu diesen Angaben den Berichtsgegenstand „Beschäftigungsverhältnisse“ sowie das „Verbindungspapier“" ${ }^{11}$ ). Hoffmann und Walwei ermitteln auf der Basis des Mikrozensus für Westdeutschland im Vergleich der Jahre 1985 und 2000 einen leichten Anstieg des Anteils der abhängig Beschäftigung an allen Erwerbstätigen von 88,2\% auf 89,2\% (Hoffmann, Walwei 2002). Hinter dieser Entwicklung verbergen sich jedoch erhebliche Umschichtungen in der Struktur der Erwerbstätigkeit, deren wesentlichen Merkmale der anteilige Rückgang unbefristeter Vollzeitbeschäftigter zugunsten vor allem von (befristeter, überwiegend jedoch unbefristeter) Teilzeitbeschäftigung, aber auch wachsende Anteilen anderer Erwerbsformen sind:

\section{Teilzeitbeschäftigung}

Zwischen 1960 und 1990 steigt die Teilzeitquote, d.h. der Anteil der Teilzeitbeschäftigten an allen (hier: abhängigen) Beschäftigten von 2,6\% auf 15,5\%, was bekanntermaßen vor allem auf die zunehmende Zahl weiblicher Teilzeitbeschäftigter zurückgeht: Die „Männerquote“ da/IAB, in dem spezifische Aspekte der Einordnung des Berichtsgegenstandes „,Beschäftigungsverhältnis$\mathrm{se}^{\text {“ }}$ in den Gesamtkontext der Berichterstattung diskutiert werden. 
liegt 1990 mit 2,2,\% kaum über dem Wert von 1960 - damals waren es 0,6\% -, während die „Frauenquote“ von 6,4 auf knapp 34\% steigt. In der gesamtdeutschen Betrachtung steigt die Teilzeitquote nach 1990 deutlich an und erreicht 1998 einen Wert von 18,8\% (Männer: 4,1 und Frauen 36,5\%). ${ }^{12}$ Betrachtet man die Struktur, dann ist - allseits bekannt - Teilzeitarbeit vor allem „Frauenarbeit“ - und zwar vor allem eine Beschäftigungsform von Angestellten (3,5 Mio. Teilzeitbeschäftigte), gefolgt von ArbeiterInnen (knapp 2 Mio.). Teilzeit spielt dagegen bei Selbständigen oder Beamten eine vergleichsweise geringe Rolle (Klammer, Tillmann 2001, S. 51). Und: Teilzeit ist eher eine Beschäftigungsform für Niedrigqualifizierte: Die BIBB/IAB-Erhebung 1998/99 zeigt, daß die Teilzeitquote von Beschäftigten ohne Ausbildungsabschluß (d.h. der Anteil von Teilzeitbeschäftigten an allen Beschäftigten dieser Qualifikationsstufe) mit rund 38\% deutlich vor allen anderen Qualifikationsgruppen liegt. Allerdings ist Teilzeitarbeit mitnichten nur Angelerntenarbeit: Die Teilzeitquoten von Universitäts- und FachhochschulabsolventInnen sind zwar die geringsten, mit knapp 20\% (Uni) bzw. etwa 16\% (Fachhochschule) jedoch auch nicht zu vernachlässigen (Parmentier 2000, S. 28).

\section{Geringfügige Beschäftigung}

Für die Entwicklung der geringfügig Beschäftigten lassen sich keine gesicherten Daten vorlegen. Sicher ist aber - bei allen erheblichen Unterschieden zwischen den einzelnen Datenquellen -, daß deren Zahl in Westdeutschland seit Mitte der 80er Jahre vergleichsweise stark und insgesamt kontinuierlich angestiegen ist: Jährliche Wachstumsraten zwischen - je nach Datenbasis - 4,1 und 5,7\% führen zu einem Anteil an allen Beschäftigten von 10\%. Dieser Anteilswert ist allerdings nur bedingt aussagekräftig, da das individuell oftmals sehr geringe Arbeitsvolumen dann überbewertet würde. Umgerechnet in Vollzeitvolumina ergäbe sich für das Jahr 1997 eine virtuelle Zahl von 1,65 Mio. „Vollzeitbeschäftigten“ mit geringfügigem Beschäftigungsverhältnis, die einen Anteil von knapp 5\% am gesamten Arbeitsvolumen hätten (vgl. Buch 1999, S. 147ff.).

\section{Befristete Beschäftigung}

Der Anteil der befristet Beschäftigten (Voll- und Teilzeit) an allen Arbeitern und Angestellten steigt in Westdeutschland zwischen 1985 und 1999 von 5,4\% auf 7,1\%. In Ostdeutschland 
steigt die Befristungsquote von 12,6\% nach leichten Rückgängen im Verlauf der 90er Jahre auf 13,1\% im Jahr 2000. Am Ende der 90er Jahre gibt es ca. 1,6 Mio. befristet Beschäftigte in West- und rd. 700 Tsd. in Ostdeutschland. Wie im Berichtsgegenstand „Unternehmens- und Arbeitsorganisation“ ausführlicher dargestellt, erfolgt der größte Teil der Anteilsveränderung bzw. der Zunahmen befristeter Beschäftigung in der zweiten Hälfte der 90er Jahre. Bemerkenswert ist dabei zum einen, daß Befristungen im Westen wie im Osten vor allem die jüngeren Kohorten und insbesondere Berufseinsteiger trifft. Und zum anderen, daß Befristungen eine nach dem Qualifikationsniveau tendenziell polarisierende Wahrscheinlichkeit aufweisen: Befristungen betreffen überproportional Un- oder Geringqualifizierte, aber ebenso auch Personen mit einem Fachhochschulabschluß oder einer Universitätsausbildung. Frauen weisen gegenüber Männern nur geringfügig höhere Befristungsquoten auf (vgl. auch den Berichtsgegenstand „Beschäftigungsverhältnisse“).

\section{Leiharbeitnehmer}

Wie im Berichtsgegenstand „Beschäftigungsverhältnisse“ ausführlicher dargestellt, hat sich die Anzahl der Leiharbeitnehmer vor allem in der zweiten Hälfte der 90er Jahre verdoppelt: 1992 gab es in Deutschland insgesamt 1,4 Mio. Leiharbeitnehmer, zum Jahrhundertwechsel waren es bereits 3,4 Mio. Leiharbeit ist nach wie vor überwiegend eine Männerdomäne, allerdings steigt die Frauenquote leicht an: Von 19,5\% 1992 auf 22,5\% im Jahr 2000. Leiharbeit ist vor allem - aber nicht nur - eine Beschäftigungsform von Niedrigqualifizierten und von Jüngeren. Die Anteil von Niedrigqualifizierten und von Jüngeren sind jeweils im Vergleich mit der Gesamtbeschäftigung deutlich überproportional (Jahn, Rudolph 2002). Allerdings bleibt der Anteil an allen Erwerbstätigen - trotz der beachtlichen Zunahme - mit rund 0,9\% im Jahr 2000 immer noch recht bescheiden (Hoffmann, Walwei 2002).

\section{Selbständige}

Der Zahl der Selbständigen außerhalb der Landwirtschaft ist zwischen 1981 und 1997 im früheren Bundesgebiet von etwa 1,7 Mio. Personen auf rund 2,7 Mio. Personen im Jahr 1997 angestiegen (vgl. Buch 1999). Im Jahr 2000 sind rund 3,6 Mio. Erwerbstätige selbständig (3,1 in West und 0,5 Mio. in Ostdeutschland). Da zugleich die Zahl der selbständigen Landwirte weiterhin rückläufig ist, änderte sich an der Selbständigenquote insgesamt wenig: In Westdeutschland geht sie von 11,8 auf 11,3\% zurück, dagegen klettert der Anteil der Selbständigen außerhalb der Landwirtschaft in Westdeutschland von 8,1\% im Jahr 1985 auf 9,8\% im Jahr 
2000 (in Ostdeutschland liegt diese Selbständigenquote bei 8,3\%). Die wachsende Bedeutung der Selbständigkeit innerhalb der Erwerbsstrukturen geht dabei vor allem auf die steigende Zahl von Ein-Personen-Selbständigen, d.h. von Selbständigen ohne weitere Beschäftigte zurück: Während der Anteil der Selbständigen mit Beschäftigten im Westen zwischen 1985 und 2000 nur von 4,5 auf 4,7\% steigt, wächst der Anteil der Ein-Personen-Selbständigen von 2,9 auf 4,6\% (Ostdeutschland: 3,9\%). Selbständige sind überwiegend Männer (rd. 70\%) und weisen im Durchschnitt deutlich überproportional hohe Bildungsabschlüsse auf (Frick u.a. 1999).

\subsection{Zusammenfassung}

Zusammenfassend läßt sich festhalten, daß die Erosion des Normalarbeitsverhältnisses vor allem ein Prozeß der Differenzierung und Pluralisierung der Erwerbsformen ist (vgl. Klammer, Tillmann 2001), der vornehmlich den wachsenden Anteilen Teilzeitarbeit und anderer Erwerbsformen jenseits des „Normalarbeitsverhältnisses“ zuzuschreiben ist. Der Begriff der Erosion bezeichnet daher auch vor allem den Bedeutungsrückgang eines institutionellen Arrangements, daß für die fordistisch-tayloristische Organisation von Arbeit in normativer wie in struktureller Hinsicht als ,prägend“ gilt. Schaut man jedoch nicht nur auf die unspektakulär wirkende Gesamtentwicklung der Erwerbstätigkeit, dann werden drei beachtenswerte Entwicklungen sichtbar:

(1) Betrachtet man die Struktur der Erwerbsformen im einzelnen, dann scheinen sich diese im Großen und Ganzen in die bekannten Ungleichheitssyndromatik zu fügen: Flexible Beschäftigung ist in vielen Fällen die „Domäne“ von Geringerqualifizierten (Männern, vor allem aber Frauen) und damit der „klassischen“ Gruppe von Jedermannsarbeitskräften. Zu vermuten ist dann auch, daß sich an der zugrundeliegenden Flexibilisierunglogik betrieblicher Beschäftigungspolitik wenig geändert haben dürfte. Anders ausgedrückt: Die Heterogenität der Erwerbsformen und der hier jeweils überwiegenden oder dominierenden Arbeitskräftegruppe ist auch ein Indiz für gewissermaßen traditionelle Segmentationslinien und Flexibilisierungslogiken.

(2) Auf der anderen Seite erweist sich aber auch die „,innere“ Struktur der Erwerbsformen als heterogen, zuweilen sogar polarisiert: Dieser Befund deutet dann jedoch darauf hin, daß an der These eines Umbruchs betrieblicher Flexibilisierung etwas dran sein könnte, weil nun auch die Beschäftigung von Qualifizierten und Hochqualifizierten offensichtlich in einer Art „lockereren Bindung“ an den Betrieb organisiert wird. Dies spricht dann jedoch auch dafür, 
daß die gedachten Segmentationslinien zwischen verschiedenen Erwerbsformen oder eben auch Flexibilisierungsstrategien (zunehmend?) zu undifferenziert sind: Vor allem die befristete Beschäftigung von Hochqualifizierten und die steigende Zahl von Ein-PersonenSelbständigen (von denen viele als Freie Mitarbeiter für Unternehmen tätig sein dürften) deutet darauf hin, daß hier numerische und funktionale Flexibilisierungsstrategien möglicherweise neuartig kombiniert werden - mit noch kaum geklärten Implikationen für die Analyse von Beschäftigungspolitiken, Ungleichheitsstrukturen, Erwerbsverläufen, sozialer Sicherheit etc.

(3) Noch nicht eindeutig interpretierbar ist die Beobachtung der höheren Anteile von Jüngeren an einzelnen Erwerbsformen. Hier steht die Frage im Raum, ob es sich dabei um ein biographisches oder ein erwerbsstrukturelles Phänomen handelt, d.h. vornehmlich um eine Veränderung von Erwerbsbiographien oder - qua intergenerationellem Wandel - um die strukturelle Verfestigung neuer Erwerbsformen.

\section{Flexibilisierung der Arbeitszeit}

\subsection{Thesen und Ansatz}

\section{Fragestellung und Thesen}

Die Flexibilisierung und Extensivierung der Arbeitszeit sind Indikatoren veränderter Prinzipien der Organisation des Einsatzes von Arbeitskraft in den Unternehmen. Dieser neue Flexibilisierungsmodus zeichnet sich durch drei Prinzipien aus:

Erstens ist die tendenzielle Erosion des „Normalarbeitstages“ Ausdruck einer Individualisierung der Arbeitszeit. Deren Kern ist die partielle oder vollständige Auflösung der standardisierten, jeweils für Kollektive gültigen täglichen Arbeitszeit. Das ist ein Bruch mit traditionellen Flexibilisierungsansätzen, die in allererster Linie auf die Flexibilisierung der Organisation (so eben die klassische Schichtarbeit in der Produktion) abzielen. Die damit jeweils verbundene individuelle Flexibilität blieb eine abgeleitete Folge und war gewissermaßen „stan-

dardisierte Flexibilität“. ${ }^{13}$ Die Individualisierung des flexiblen Arbeitseinsatzes hat nach den 
hier vorliegenden Befunden noch eine weitere, im Kern personalpolitische Ursache: Sie ist eine Folge der knappen Personalbemessung, die es mit sich bringt, daß es immer weniger Möglichkeiten des wechselseitigen Ersetzens, Aushelfens, Ausgleichens gibt. Organisationelle Flexibilität stellt sich damit zunehmend über individuelle Flexibilität her. Das bedeutet im Umkehrschluß, daß die Fähigkeit einer Organisation, flexibel auf Veränderungen zu reagieren, immer mehr von der jeweils individuellen Flexibilität abhängt. ${ }^{14}$

Als zweites Prinzip kann gelten, daß Anfang und Ende des Arbeitstages vor allem von den jeweils anfallenden externen Anforderungen abhängig sind. Dieses Prinzip verweist auf den weiteren Rahmen der Organisation des Arbeitseinsatzes, der als Vermarktlichung und indirekte Steuerung beschrieben wurde. Die organisatorische Internalisierung des Marktes sorgt im Verein mit einem Steuerungsmodus, bei dem das Management zur Seite tritt und die Anpassung von Anforderungen und den zu ihrer Bewältigung notwendigen Ressourcen vermehrt den Arbeitskräften selbst überläßt, für eine Vermarktlichung des zeitlichen Arbeitseinsatzes. Für Anfang und Ende des Arbeitstages existiert zwar noch ein Rahmen, innerhalb dessen (und zum Teil auch außerhalb dessen) orientiert sich die individuelle Arbeitszeit aber dem Prinzip nach an den jeweils virulenten (Außen-)Anforderungen. Der Übergang von kollektiver zu individueller Flexibilität ist gleichzeitig ein Moment der Herstellung höherer Unmittelbarkeit zwischen Markterfordernissen und individuellem Arbeitseinsatz, die ihrerseits wiederum zu einem zentralen Steuerungsmoment wird. Anders formuliert: Einerseits wird die Organisation von der individuellen Flexibilität abhängig, andererseits setzt sie die Individuen unmittelbarer dem Markt/Kunden aus und macht deren Arbeitseinsatz von den jeweils anfallenden Außenanforderungen abhängig.

Das dritte Prinzip, das mit den beiden ersten unmittelbar verknüpft ist, ist das Prinzip der Selbstorganisation der Arbeitszeit. Komplementär zum Verzicht auf eine kapazitätsorientierte Steuerung durch das Management, erhalten die Beschäftigten größere Spielräume bei der Bestimmung von Anfang und Ende des Arbeitstages. An die Stelle der kollektiven Regulierung oder der unmittelbaren Anweisung tritt so das Prinzip der selbstorganisierten Verfügbarkeit. Diese ist nicht ohne Rahmen: Der objektive Rahmen besteht in den nach wie vor existenten

Kollektive und ist zweitens standardisiert in der Form, daß ein Schichtarbeiter regelmäßig zu ,,atypischen“ Arbeitszeiten arbeitet und dies vorher auch weiß. gründung für die weitverbreitete Vorstellung, ,olympiareife“ Belegschaften müßten auch ,junge“ Belegschaften sein. 
institutionellen Grenzen, die den individuellen Gestaltungsspielraum in zumindest teilweise festgelegte Korridore verweist, es besteht aber auch darin, daß Vorgesetzte zwar stärker in den Hintergrund gerückt, aber gleichwohl nicht verschwunden sind. Auch gesetzte Termine, die unmittelbare Konfrontation mit Kundenanforderungen oder die Notwendigkeit der Kooperation mit anderen setzen dem individuellen Gestaltungsspielraum Grenzen. Auf der Suche nach Begründungen insbesondere für die Selbstorganisation von Mehrarbeit stößt man jedoch auch auf die Wirkungsmächtigkeit informeller Grenzen der individuellen Selbstorganisation des Arbeitseinsatzes: Die jeweilige „Leistungskultur“ der Projekt- oder Arbeitsgruppe, der Abteilung oder des Bereichs; der Umstand, daß Arbeit angesichts knapper Personalressourcen ein Nullsummenspiel ist, bei dem die eigene Zurückhaltung in puncto Arbeitszeit fast zwangsläufig anderen Mehrarbeit beschert. Informelle Grenzen resultieren auch aus den Argumenten oder Appellen von Vorgesetzten oder Kollegen im Rahmen von „diskursiven“ Steuerungs- und Koordinationsformen. Und vor allem stößt man auf die systematische Überlastung: Die Selbstorganisation der Arbeitszeit ist vor diesem Hintergrund für viele immer zugleich Selbstorganisation des Arbeitseinsatzes angesichts wachsender und variabler zeitlicher Anforderungen. Hielscher und Hildebrandt sprechen in diesem Zusammenhang von einem „Flexibilisierungsparadox“, das darin besteht, „... daß die formal ausgeweiteten Dispositionsmöglichkeiten über die Lage der Arbeitszeit und der Freizeit mit den steigenden Arbeitsanforderungen kollidieren. Die Flexibilität läßt sich unter diesen Bedingungen nicht in Zeitsouveränität für die Beschäftigten umsetzen. Im Gegenteil: sie mündet in den Zwang, die individuelle Arbeitszeit allein auf das hohe Arbeitspensum hin zu optimieren“" (Hielscher, Hildebrandt 1999, S. 79).

Flexible Arbeitszeiten hat es immer schon gegeben. Der wesentliche Unterschied, das „Neue“ besteht nun zum einen darin, daß das individuelle Arbeitsvolumen zur Variable und das Subjekt zum Akteur der Organisation der Arbeitszeit wird. Es läßt sich somit ein Wandel der Bezugsgröße und des Regulationsmodus der Arbeitszeitorganisation beobachten: Einen Wandel von der kollektiven zur individuellen und von der fremdorganisierten zur selbstorganisierten Arbeitszeit. Der zweite wesentliche Unterschied besteht in der höheren Unmittelbarkeit von Arbeitszeitgestaltung und Markterfordernissen. In dieser Perspektive ist die Selbstorganisation der Arbeitszeit die komplementäre Organisationsform zur organisatorisch umgesetzten und in den Fallbetrieben vielbeschworenen - Kundenorientierung. 


\section{Ansatz}

Die Flexibilisierung der Arbeitszeit soll sowohl auf der betrieblichen wie auf der individuellen, in den objektiven Strukturen wie in ihrem Subjektbezug analysiert werden.

\begin{tabular}{|c|c|c|}
\hline & Betriebliche Ebene & Individuelle Ebene \\
\hline Objektiv & $\begin{array}{ll}\text { - } & \text { Betriebliche Arbeitszeit- } \\
\text { politik und -organisation } \\
\text { - } & \text { Verbreitung und „Prinzip“ } \\
\text { neuer Modelle der Ar- } \\
\text { beitszeitorganisation }\end{array}$ & 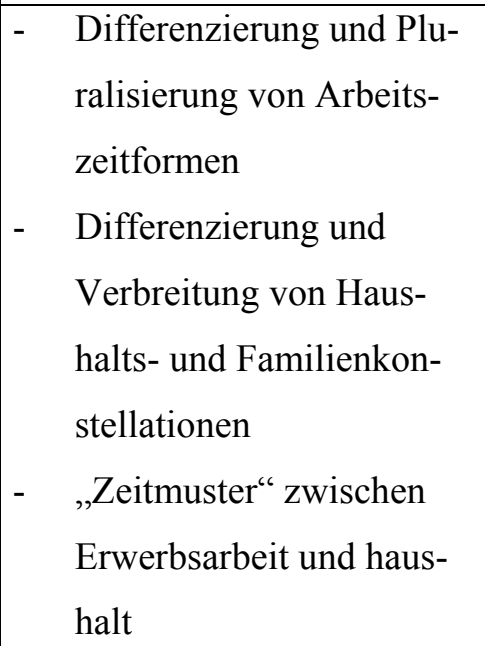 \\
\hline Subjektiv & 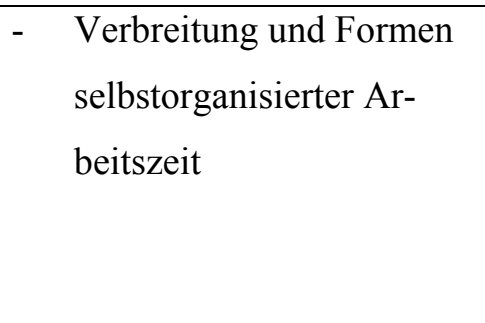 & $\begin{array}{ll}\text { - } & \text { Subjektive Gestaltung des } \\
& \text { verhältnisses von Arbeit } \\
& \text { und Leben } \\
\text { - } & \text { Wahrnehmung und Be- } \\
& \text { wertung von Zeit }\end{array}$ \\
\hline
\end{tabular}

\subsection{Befunde zur Flexibilisierung der Arbeitszeit}

\section{Arbeitszeit-generelle Entwicklungstendenzen}

\section{Arbeitszeitverkürzung}

Hinter der Verkürzung tariflicher Arbeitszeiten verbirgt sich insbesondere eine zunehmende Diversizifizierung von Arbeitszeit: Neben die „Normalarbeitszeit“ der Vollzeitbeschäftigung treten insbesondere Arbeitszeitformen wie Teilzeit und geringfügige Beschäftigung, die den seit einigen Jahren ,standardisierten` Erwerbsumfang von 35 bis 40 Wochen unterschreiten. Gleichzeitig wächst der Anteil von Beschäftigten, die das wöchentliche Volumen einer normgeprägten Arbeitszeit erheblich überschreiten. Dies bedeutet, daß der Anteil der Beschäftigten schrumpft, die im normgeprägten Arbeitszeitkorridor von wöchentlich 30 bis 40 Stunden arbeiten. Die beobachtete Entgrenzung von vertraglicher und tatsächlicher Arbeitszeit (siehe 
auch Wagner 2001) führt insbesondere für hochqualifizierte Angestellte zu einer Extensivierung ihrer tatsächlichen Arbeitszeit.

Mit diesen Diversifizierungstendenzen gehen Tendenzen einer Polarisierung entlang der Dimensionen Geschlecht und Qualifikation einher: Eine geschlechtsspezifische Polarisierung ergibt sich aus der gleichzeitigen Zunahme kurzer Arbeitszeiten von Frauen (insbesondere in Form von Teilzeit und geringfügiger Beschäftigung) und langer Arbeitszeiten von Männern die Arbeitszeitunterschiede zwischen Männern und Frauen haben sich im Zeitverlauf vergrößert. Auch die Arbeitszeitunterschiede zwischen den Qualifikationsstufen steigen - während untere Qualifikationsgruppen eher niedrigere Arbeitszeiten aufweisen, erfahren hochqualifizierte Beschäftigungsgruppen eine Arbeitszeitextensivierung, die scheinbar mit neueren Formen der Organisation und Steuerung von Arbeitszeit wie Zeitkontenmodelle, Vertrauensarbeitszeit und Zielvereinbarungen in Verbindung stehen.

\section{Zunehmende Erwerbsbeteiligung von Frauen}

Ein weiterer Aspekt in der langfristigen Entwicklung der Arbeitszeit ist die wachsende Erwerbsbeteiligung von Frauen. Dabei muß allerdings zwischen Ost- und Westdeutschland unterschieden werden. Betrachtet man die Zeitverwendung von 1965/66 so fallen die verschiedenen Leben von Frauen in den beiden Ländern auf ${ }^{15}$. Während für Frauen in der DDR die Beteiligung am Erwerbsleben im hohen Umfang eine Normalität darstellte, war das Leben von Frauen in der Bundesrepublik häufiger ausschliesslich von Lebensbereichen wie Ehe und Familie geprägt. Eine Vereinbarkeit von Erwerbstätigkeit und Familienverantwortung für Frauen war eher eine Ausnahme und kein selbstverständlicher Alltag. In der Bundesrepublik bestanden demnach eine stärker wirksamere geschlechtsspezifische Rollenverteilung, die sich in der Zeitverwendung durch größere Unterschiede zwischen Männern und Frauen in den Tätigkeiten Erwerbsarbeitszeit auf der einen Seite und der Familienarbeit auf der anderen Seite bestätigen. In der DDR fallen diese Unterschiede wesentlich geringer aus. Dieses unterschiedliche Ausgangsniveau führt dazu, daß sich eine verstärkte Erwerbsbeteiligung von Frauen in den alten Bundesländern als wachsende Angleichung der Geschlechter interpretieren läßt, während die Angleichung der Geschlechter in Spähren der Erwerbs- und Familienarbeit für die neuen Bundesländern eher stagniert bzw. zum Teil sogar rückläufig ist. 


\section{Flexibilisierung und Selbstorganisation der Arbeitszeit}

Eine weitere, seit längerem beobachtbare, Entwicklungstendenz ist die Variabilisierung der Arbeitszeit innerhalb der Arbeitswoche und eines Arbeitstages in Verbindung mit wachsenden Gestaltungsspielräumen der Beschäftigten: So geben in einer Erhebung des ISO-Instituts $17 \%$ der Beschäftigten (18\% in West- und 13\% in Ostdeutschland) an, ihre Lage und Dauer der Arbeitszeit überwiegend selbst bestimmen zu können. Die Erfahrung von Arbeitszeitsouveränität korrespondiert stark mit der beruflichen Stellung: So erfahren sich Beschäftigte mit höheren Qualifikationen zu 25\% als arbeitszeitsouverän, während dies für untere Qualifikationsgruppen wesentlich weniger häufig zutrifft (Bundesmann-Jansen u.a. 1999, S.15). Auch die jeweilige Arbeitszeitorganisation beeinflußt die erlebte Arbeitszeitsouveränität: Beschäftigte, die in hochflexiblen Gleitzeitmodellen arbeiten, geben mit 31\% weitaus häufiger an, selbst über Lage und Dauer der Arbeitszeit bestimmen zu können, als Beschäftigte, die in der zwar verläßlichen, aber meist starren Schicht- und Nachtarbeit tätig sind (5\%) (Siehe Bundesmann-Jansen u.a. 1999, S. 15). Allerdings ist die faktische Nutzbarkeit formaler Gestaltungsoptionen in aller Regel stark von betrieblichen Kontexten beeinflußt (Promberger 2001, S. 627).

Die Datenlage zur Flexibilisierung der Arbeitszeit ist jedoch relativ dünn und zum Teil unzureichend. So wird die Arbeit außerhalb des Normalarbeitszeitstandard häufig durch regelmäBige Schicht- und Nachtarbeit sowie regelmäßige Wochenendarbeit operationalisiert (so auch in den ISO-Erhebung). Diese Formen der Erwerbsarbeit sind jedoch häufig durch die Arbeit in der Dienstleistungsbranche oder Industriebetrieben strukturell bedingt und vertraglich mit den Beschäftigten geregelt und sind somit keine Formen individueller Arbeitszeitflexibilisierung. Uns interessiert vielmehr, ob die oben skizzierte Extensivierung von Arbeitszeit durch eine Entgrenzung von vertraglicher und tatsächlicher Arbeitszeit sowie neuere Arbeitszeitformen, die die Selbstorganisation der Arbeitszeit implementieren, in eine Flexibilisierung der Arbeitszeitlage führen. Einen ersten Hinweis geben Ergebnisse des Mikrozensus: Nach diesen Daten läßt sich keine Veränderung der ständigen und regelmäßigen Arbeit an Wochenenden im Jahr 2000 im Vergleich zu 1991 nachweisen. Es findet sich jedoch ein wachsender Anteil von Beschäftigten, die gelegentlich an Samstagen bzw. an Sonn- und/oder Feiertagen arbeiten. Neben Beschäftigtengruppen, deren de-standardisierte Arbeitszeit strukturell bedingt und meist auch vertraglich fixiert ist, treten Beschäftigte, für die diese strukturellen Zwänge der Gestaltung der von Erwerbsarbeitszeit ausserhalb der Normalarbeitszeit nicht konstitutiv sind. So scheint es zumindestens für höherqualifizierte Angestellte selbstverständlicher zu werden, 
daß Arbeit in Form von (meist unbezahlten) Überstunden abends bzw. während des Wochenendes geleistet wird (Wagner 1999/2000).

\section{Betriebliche Arbeitszeitorganisation}

Aus betrieblicher Sicht steht hinsichtlich der Arbeitszeitorganisation primär die Anpassung des Arbeitsvolumens an die je gegebenen Anforderungen und somit an die Dauer und Flexibilität von Betriebszeiten im Vordergrund: „Lange Betriebszeiten gelten in der Regel als ein Indikator für Wettbewerbsfähigkeit und Standortqualität. Flexible Betriebszeiten bezeichnen das Potential von Betrieben, die Betriebszeiten an schwankende Produktion möglichst friktionslos und schnell anpassen zu können (Bauer u.a. 2002, S. 15). Wesentliches Instrument zur Flexibilisierung der Betriebszeiten ist die Entkoppelung der Betriebszeiten. ${ }^{16} \mathrm{Um}$ die Betriebszeit zu erhöhen werden auf betrieblicher Seite insbesondere Arbeitszeitmaßnahmen eingesetzt (ebd., S. 20). Wachsende Bedeutung erhalten dabei insbesondere Arbeitszeitmodelle, in deren Mittelpunkt die (häufig kostenneutrale) Flexibilisierung der individuellen Arbeitszeit und die Übertragung eines Teils der Organisationskomepetenz auf die Beschäftigten (Selbstorganisation) stehen: Dies sind insbesondere Gleitzeitregelungen, Zeitkontenmodelle sowie die Abschaffung der Zeiterfassung durch den Betrieb („Vertrauensarbeitzeit““): ${ }^{17}$ In Gleitzeitregelungen ist der Arbeitsumfang festgelegt, aber Beginn bzw. Ende des Arbeitstages sind, meist mit Ausnahme von Kernarbeitszeiten, variabel. Auch in Arbeitszeitkontenmodellen sind die Beschäftigte gefordert, die Dauer ihrer Arbeitszeit nach dem jeweiligen Arbeitsumfang zu richten. Mehrarbeit in Zeiten hohen Arbeitsaufwandes wird auf Zeitkonten ,gesammelt ${ }^{\text {‘ }}$ und soll in Zeiten geringeren Arbeitsaufwandes in Form von Freizeitausgleich abgetragen werden. Orientiert sich allerdings die Personalbemessung eher an einem niedrigem Arbeitsanfall, und dies scheint zunehmend gängig zu sein, führen Kontenmodelle häufig zu einem hohen Zeitguthaben. Bleibt die Auslastung dauerhaft hoch, dann führen Kontenmodelle insgesamt zu einer Extensivierung von Arbeitszeit, da es den Beschäftigten dann häufig nicht möglich ist, ihre Zeitguthaben in Form von Freizeit abzubauen. Die Zeitguthaben werden dann monetär vergütet - oder sie verfallen (ebd., S. 29). Am höchsten ist die Anforderungen an die Selbstorganisation der Arbeitszeit im Modell der Vertrauensarbeitszeit. Hier wird vom Unternehmen

Entkoppelung der Betriebszeit beschreibt das Verhältnis der Länge der Betriebslaufzeit zur vertraglich vereinbarten Wochenarbeitszeit der Vollzeitbeschäftigten 
vollständig auf die Erfassung der Arbeitszeit verzichtet und die Arbeitszeit von der Leistungsbeurteilung ausgeklammert. Für die Beschäftigten ist die „Entkoppelung von Arbeitsund Anwesenheitszeit" (Haipeter u.a. 2002, S. 5) die entscheidende Dimension, da vorausgesetzt wird, das sie „eigenverantwortlich zwischen produktiver, im Sinne der Erzielung des angestrebten Arbeitsergebnisses verausgabter Arbeitszeit, und unproduktiver Arbeitszeit, d.h. bloßer Anwesenheitszeit unterscheiden müssen“ (ebd.). Dies impliziert die Beurteilung und Bewertung verschiedener Tätigkeiten durch die Beschäftigten selbst.

Alle drei Arbeitszeitorganisationsformen zeichnen sich durch - allerdings unterschiedliche Anforderungen an die Selbstorganisation der Beschäftigten aus. In aller Regel sind der Selbstbestimmung über Dauer, Lage oder Verteilung der Arbeitszeit betriebliche Grenzen gesetzt. Die Beschäftigten müssen zunehmend betriebliche Anforderungen erkennen - dies setzt eine Internalisierung von betrieblichen Zielen bzw. des Marktes voraus - und seine Arbeitsorganisation und damit verbunden seine Arbeitszeit darauf abstimmen (Vermarktlichung des zeitlichen Arbeitszeiteinsatzes). Da Arbeit häufig im Kontext von Gruppenarbeit und in engem Zusammenspiel mit Kollegen organisiert ist, wird auch hier eine zunehmende Abstimmungsleistung der Beschäftigten untereinander verlangt. Und zu allerletzt ist der $\mathrm{Be}-$ schäftigte für die Erfüllung eigener Bedürfnisse des Arbeitszeitumfanges und -lage und der Vereinbarkeit seiner Erwerbstätigkeit mit lebensweltlichen Anforderungen verantwortlich. So ist auch kein Wunder, daß individuelle Arbeitszeitregelungen am häufigsten bei qualifizierten und hochqualifizierten Beschäftigten zu finden sind. Gleichzeitig stellt sich nun organisationelle Flexibilität primär über individuelle Flexibilität her. Der Betrieb wird zunehmend von der individuelle Flexibilität ihrer Beschäftigten und ihrer individuellen Anpassungsleistungen an den Markt abhängig. Der Versuch, über die Entkoppelung von Arbeitszeit und Betriebszeiten die Anpassungsfähigkeit an dynamische Anforderungen und Bedingungen zu erhöhen, führt zur einer neuartigen Verkoppelung von betrieblicher und individueller Flexibilität.

\section{Wahrnehmung und Bewertung flexibler Arbeitszeiten}

In neuen Arbeitszeitorganisationen sind Optionen zugunsten einer höheren Arbeitszeitsouveränität enthalten und ermöglichen eine höhere Selbstgestaltung von Arbeitszeit. Damit stellt sich die Frage nach der Wahrnehmung und Bewertung solcher Arbeitszeitmodelle durch die Beschäftigten. Diese Frage stellt sich in lebensweltlicher Perspektive, da nun - zumindest der Theorie nach - den Beschäftigten größere Spielräume auch bezüglich der Gestaltung des Verhältnisses von Arbeit und Leben eingeräumt werden. Sie stellt sich aber auch 
aus betrieblicher Sicht, da - wie gesehen - die Betriebe in ihrer Flexibilität ja nun mehr und mehr von der Flexibilität der Beschäftigten abhängig werden.

Die ISO-Erhebung von 1999 zeigt diesbezüglich, daß 84\% der Gleitzeitbeschäftigten in der Gleitzeitarbeit eher Vorteile und nur 2\% darin Nachteile sehen (Bundesmann-Janßen u.a. 2000, S. 12). Die Akzeptanz von Arbeitszeitkontenmodellen ist demgegenüber weniger deutlich. „Hier sind es $42 \%$ der Beschäftigten, die angeben, daß die Vorteile überwiegen. Zwar sehen nur 13\% der Beschäftigten in Zeitkonten Nachteile; aber 45\% sind indifferent: für sie halten sich Vor und Nachteile die Waage“ (ebd.). Überstunden werden von Beschäftigten überwiegend abgelehnt, häufig werden diese Mehrarbeiten auch nicht bezahlt. Bei den Gründen für Überstundenarbeit stehen betriebliche oder arbeitsorganisatorische Arbeitszwänge im Vordergrund (Gross, Munz 2000, S. 22 ff.).

Die erhöhte Arbeitszeitsouveränität wird jedoch häufig durch längere Arbeitszeiten und gröBere Planungsunsicherheit erkauft. Die Nagelprobe für die faktische Nutzbarkeit flexibler Formen der Arbeitszeitorganisation stellt jedoch die Synchronisierbarkeit von Arbeitszeiten mit familialen Zeitstrukturen dar (Promberger 2001, S. 630). Wenn diese nicht gegeben ist, nimmt die Akzeptanz und Zufriedenheit mit hochflexiblen Arbeitszeiten ab und die subjektiv empfundene Zeitnot steigt. Flexible Arbeitszeitorganisation führt demnach nicht automatisch zu einem höheren Zeitwohlstand und zu höherer Zeitautonomie - es deutet sich eher das Gegenteil an. Flexibilisierung der Arbeitszeit führt eher zu deren Extensivierung, so daß es kein Wunder ist, daß empirische Untersuchungen (vgl. Schupp 1998, Groß, Munz 2000) nachweisen, daß ein wachsender Anteil der Beschäftigten eine Reduktion der tatsächlichen Arbeitszeit wünscht. Erstrebenswert ist für die Beschäftigten weniger eine Reduktion der vertraglichen Arbeitszeit oder ein gänzlich anderes Arbeitszeitmodell (etwa eine Teilzeitbeschäftigung), sondern die Anpassung der durch Mehrarbeit entstehenden tatsächlichen Arbeitszeit an die vertraglich ausgehandelte und bezahlte Arbeitszeit.

Auch verdichten sich Hinweise, daß flexible Arbeitszeiten mit Zeitnot und Zeitstress korrespondieren. So sind von Zeitnot überproportional Beschäftigte mit flexiblen Arbeitszeiten und überlangen Wochenarbeitszeiten betroffen (Bundesmann-Janßen u.a. 2000, Garhammer 2000, S. 237). Das Gefühl von Zeitnot und Streß bezieht sich nicht nur auf den Bereich der Erwerbsarbeit, gerade das Spannungsfeld von Erwerbsarbeit mit anderen Verpflichtungen wie Hausarbeit und Kinderbetreuung und die Koordination verschiedener lebensweltlicher Anforderungen korrespondieren mit dem Gefühl der Zeitnot. 
Auch wenn sich die Gesamtarbeitsbelastungen (zusammengesetzt aus bezahlter und unbezahlter Arbeit) zwischen den Geschlechtern weniger unterscheiden als man vielleicht vermuten mag (Blanke 1996), so unterscheiden sich die Tätigkeiten innerhalb der bezahlten Arbeit und der unbezahlten Arbeit grundlegend voneinander und bergen ein unterschiedliches Belastungspotential. Während für Tätigkeiten innerhalb der Erwerbsarbeit feste Ziel- und somit Zeithorizonte festgelegt werden und nach der täglichen Erledigung der Feierabend lockt, können Hausarbeiten und Kinderbetreuung nicht auf einen festgelegten Zeitraum beschränkt werden. „Unaufschiebbarkeit einerseits und unterbrochene Handlungsabläufe von Aktivitäten anderseits prägen den Alltag der Arbeit im Haushalt. ${ }^{18}$ Gerade dann, wenn kleine Kinder im Haushalt sind, werden Handlungsabläufe ständig unterbrochen. Arbeitsprozesse, die wenige Minuten dauern, ziehen sich wesentlich länger hin und werden deshalb zum Streß“ (Blanke 1996, S. 190). Auch übernehmen Frauen mit dem Großteil der Hausarbeit auch die Verantwortung für diese Tätigkeiten und haben weniger eindeutig festlegbare freie Zeiträume, in denen sie vollkommen abschalten können.

Durch die abbildbare Quantität von Zeitverwendung wird noch nichts über die Qualität der Zeit und daraus möglichen Stressfaktoren ausgesagt. Wer einer hohen Belastung mit verschiedenen Verpflichtungen gegenübersteht, wird - um alles zu erledigen - seine Arbeiten wahrscheinlich beschleunigen und gut organisieren, wird auf die Erledigung einiger Dinge verzichten (z.B. das Umdekorieren der Wohnung) und bei notwendigen Tätigkeiten die Ansprüche verringern (z.B. die Zubereitung eines aufwendigen Essens zugunsten einer einfacheren Mahlzeit). Eine Intensivierung und Rationalisierung von Arbeitszeit läßt sich auch bei anderen Tätigkeiten der Hausarbeit vermuten. ${ }^{19}$ Selbst die physiologische Regeneration wie der tägliche Schlaf, die Zeit für Essen und Körperpflege wird reduziert, der Zeitablauf im Alltag wird somit verdichtet, „d.h. weniger Schlaf, weniger Möglichkeiten zum Ausruhen und weniger Muße für Mahlzeiten“ (Garhammer 1999, S. 462).

So finden Aktivitätenwechsel überdurchschnittlich häufig bei Hausfrauen statt und dies kann auf eine Zerrissenheit der Tagesgestaltung hinweisen. „Es läßt sich nichts zu Ende bringen - jedenfalls nicht an einem Stück. Dies kann ein Grund sein, weshalb sie trotz einer niedrigeren zeitlichen Gesamtbelastung als erwerbstätige Frauen mehr Zeit fordern“" (Holz 2000, S. 19) weisen, aber sich zudem auch mehr Zeit bei verschiedenen Tätigkeiten lassen können. (Vgl. auch Schwarz 1996, S. 84; Garhammer 1999, S. 472) 
Flexible Arbeitszeiten müssen - wenn sie die Möglichkeiten der Selbstorganisation von Arbeitszeit ernst nehmen - insbesondere mit lebensweltlichen Anforderungen koordinierbar sein und den Beschäftigten die Möglichkeiten geben, ihre Arbeitszeit sowohl kurzfristig an ihre Bedürfnisse anzupassen und andererseits einen langfristigen Planungshorizont zusichern, der die Absprache des eigenen sozialen Lebens mit dem anderer Sozialpartner ermöglicht. Vor allem für Beschäftigte mit Kindern ist dies eine Voraussetzung für die Vereinbarkeit von Familie und Beruf.

\subsection{Zusammenfassung}

Die Flexibilisierung von Arbeitszeit insbesondere in Form neuerer Arbeitszeitorganisation verspricht den Beschäftigten mehr Möglichkeiten zur Selbstorganisation der eigenen Arbeitszeit und somit mehr Arbeitszeitsouveränität. Allerdings richtet sich die Gestaltungsoptionen immer auch nach betrieblichen Kontexten und Einschränkungen. Arbeitszeitflexibilisierung zieht „neue individuelle und soziale Koordinationsanforderungen nach sich, durch die der Zeitgewinn der Arbeitszeitverkürzungen und der Zugewinn an Lebensqualität relativiert werden könnte“ (Herrmann-Stojanow, Rinderspacher 2001, S. 636). „Flexible Arbeitszeiten haben durchaus ernst zu nehmende Möglichkeiten eröffnet, daß die Beschäftigten über die einzelnen Schritte des Arbeitsprozesses selbst entscheiden. Doch ebenso selbstverständlich wird vorausgesetzt, daß die vorgegebenen Pensen, Projektziele und Leistungsvolumina erbracht werden; und die sind so bemessen, daß die verheißende Zeitsouveränität sich auf die Wahlfreiheit reduziert, entweder eine zusätzliche Nachtschicht einzuschieben oder das Wochenende zu opfern“ (Hensche, 2001, S. 602). Häufig sind mit flexiblen Arbeitszeiten eine Extensivierung von Arbeitszeit sowie eine Internalisierung von unternehmerischen Zielen verbunden. „Die allenthalben zu beobachtende Entwicklung wachsender Arbeitsvolumen geschieht nicht nur auf äußeren Druck. Arbeitsvorgaben, enger Zeithorizont und andere Stressfaktoren sind vielfach verinnerlicht“" (ebd., S. 603). Es ist jedoch zu klären, ob durch zunehmende Selbstorganisation und Selbstverantwortung der individuellen Arbeitszeitorganisation ein neuer und rationalisierter Umgang mit dem knappen Gut Zeit entwickelt wird. Zeit wird zum einen ein $\mathrm{Maß}$, an dem sich die eigene Effektivität mißt und deren Organisation optimiert werden soll, während sie als Maß für die eigene Arbeitsleistung und Entlohnung von betrieblicher Seite zunehmend ausgeklammert wird.

Von entscheidender Bedeutung ist jedoch, wie sich flexible Arbeitszeiten mit lebensweltlichen Anforderungen vereinbaren lassen. Insbesondere für Erwerbstätige in Paarhaushalten 
und besonders wenn Kinder zu betreuen sind, stellt die Planbarkeit unterschiedlicher Tätigkeiten und die Koordination verschiedener Anforderungen eine wichtige Voraussetzung dar. So ist es für viele Erwerbstätige nicht möglich, die individuellen Arbeitszeiten spontan zu verlängern, wenn ihre Kinder sich darauf verlassen, zu einer bestimmten Zeit z.B. von einer Tagesstätte abgeholt zu werden. Auch sind Zeitinstitutionen wie der Feierabend oder das Wochenende ein Mittel der Koordination des sozialen Lebens mit anderen. Wenn diese Zeitinstitutionen an Gültigkeit verlieren, so wird dies auch Folgen für die Vereinbarkeit von Arbeit und Leben nach sich ziehen. „Gemeinsame Aktivitäten mit Freunden und in Organisationen, in Vereinen und im Ehrenamt, die den Kern sozialer Zeit bilden, werden schwieriger abzustimmen“ (Garhammer 1999, S. 462).

Es zeigt sich zudem, daß sich eine hohe zeitliche Belastung in der Erwerbsarbeit auf Tätigkeiten jenseits der Erwerbsarbeit auswirkt. Hausarbeit muß zwar in bestimmten Umfang erledigt werden, sie wird jedoch schneller und rationalisierter durchgeführt, um noch etwas vom Tage zu haben. Auf Freizeitaktivitäten möchte man nicht verzichten, so daß als Zeitpuffer insbesondere die Mediennutzung als auch die Zeit für physiologische Regeneration (schlafen, Körperpflege, Essen) fungiert. Die Devise, weniger Fernsehen, schneller schlafen, essen und duschen scheint für viele Beschäftigte mit hoher Belastung an Erwerbsarbeit und Familientätigkeiten eine gängige Strategie zu sein.

\section{Subjektivierung von Arbeit}

\subsection{Thesen und Ansatz}

\section{Fragestellung und Thesen}

In diesem Abschnitt wird der Prozeß der „Subjektivierung von Arbeit“ behandelt. Die zentrale These ist, daß - ausgehend von Veränderungen in der Arbeitswelt, aber auch von gesellschaftlichen Veränderungstendenzen - die Bedeutung von Subjektivität und subjektiver Gestaltung in der Arbeit wächst. Hinweise auf diesen Prozeß der Subjektivierung finden sich in verschiedenen Kontexten:

- Im Kontext neuer Organisationskonzepte und Steuerungsformen (Dezentralisierung, indirekte Steuerung) oder aktueller Tendenzen der Leistungspolitik (Ergebnisorientierung, 
Vertrauensarbeitszeit) wird die aktive Beteiligung der Beschäftigten zu einem zentralen Rationalisierungspotential (vgl. Haipeter u.a. 2002; Glißmann, Peters 2001)

- Arbeits- und industriesoziologische Untersuchungen verweisen darauf, daß mit neuen Arbeitsformen (wie etwa Gruppen- oder Projektarbeit) die Anforderungen an die Selbstorganisation und Selbststeuerung der Beschäftigten steigen (vgl. Schumann u.a. 1994; Moldaschl 1994; Gerst 1997; Bollinger 2001; Kratzer 2002).

- Konzepte wie „Interaktionsarbeit“ oder „Gefühlsarbeit“" verweisen auf die zunehmende Bedeutung emotionaler Aspekte und subjektiver Eigenschaften für das Arbeitshandeln. Diese erhalten mit der weiteren Verbreitung von personenbezogenen Dienstleistungen und kundenorientierten Tätigkeiten eine wachsende Bedeutung (vgl. Büssing 1999).

- Die jüngere Forschung zum Zusammenhang von technischer Entwicklung (Automatisierung, Informatisierung) und Arbeitshandeln geht gerade nicht mehr von einer Verdrängung, sondern von einer wachsenden Bedeutung ,subjektivierendem Arbeitshandelns“ aus (vgl. Böhle 1994, 2002; Schmiede 1996).

- Die zunehmende Bedeutung lebenslangen Lernens bzw. beruflicher Weiterbildung führt in der Tendenz zu einer „Subjektivierung der Weiterbildungsplanung und -steuerung“ (Baethge, Baethge-Kinsky 2002, S. 85).

- Die Flexibilisierung und „Entgrenzung“ von Arbeit führt zu wachsenden Anforderungen an die subjektive Gestaltung des Verhältnisses von Arbeit und Leben (vgl. Hielscher, Hildebrandt 1999; Hielscher 2000; Jurczyk, Voß 2000; Kratzer 2002).

Es sind jedoch nicht die Veränderungen in Wirtschaft und Arbeitswelt alleine, die sich als Hinweise auf eine „Subjektivierung von Arbeit“ deuten lassen, sondern auch gesellschaftliche bzw. lebensweltliche Entwicklungstendenzen, so etwa:

- die Individualisierung und Pluralisierung von Haushalts- und Familienstrukturen, von Lebensformen und Lebensstilen (vgl. Beck 1986; Berger, Hradil 1990; vgl. dazu auch die Berichtsgegenstände „Haushaltsproduktion“ und „Zeitmuster“).

- eine abnehmende „Prägung“ durch die institutionellen Arrangements des fordistischen Produktions- und Sozialmodells, die - von manchen als „De-Institutionalisierung“ gefasst - als neue Gestaltungsspielräume, aber auch Zwänge für die Individuen wirksam werden (vgl. Junge 1996).

- Tendenzen einer „,normativen Subjektivierung“ im Zusammenhang mit veränderten Orientierungen (,Wertewandel“) und Individualisierungsprozessen, d.h. wachsende subjekti- 
ver Ansprüche gerade auch an die Selbstentfaltung und Selbstverwirklichung in der und durch Arbeit (vgl. Baethge 1991; Heidenreich 1996).

Entscheidende Indizien für einen Veränderungsprozeß in Richtung einer „Subjektivierung von Arbeit“" sind demnach: Neue Arbeits- und Organisationsformen, die mit neuen Anforderungen an die Selbstorganisation und Selbstregulation der Beschäftigten einhergehen und/oder den Einsatz von Subjektivität (Emotionen, Kooperationsfähigkeit, Kreativität etc.) erfordern; der Wandel von Qualifikationsanforderungen (Höherqualifzierung, soft skills etc.) und Tätigkeitsstrukturen (kunden- und/oder personenorientierte Dienstleistungen) sowie veränderte Lebensstile und Erwerbsorientierungen (normative Subjektivierung). ${ }^{20}$ Ebenfalls ,,subjektivierende“ Wirkung dürften Formen der Flexibilisierung von Arbeit, insbesondere in zeitlicher und räumlicher Hinsicht, haben, da sie mit wachsenden Gestaltungserfordernissen für die (Arbeits-)Subjekte einhergehen.

Dabei kann von vorne herein weder davon ausgegangen werden, daß es sich dabei jeweils immer um „,neue“ Entwicklungen handelt, ${ }^{21}$ noch davon, daß mit „Subjektivierung“ bereits eine flächendeckend greifende neue „Logik“ der Organisation und Rationalisierung von Arbeit $\mathrm{zu}$ beobachten wäre. Im Gegenteil ist es gerade die Frage nach Hinweisen auf deren Verbreitung, die erst zu stellen ist. Weitreichende Thesen vermuten hinter betrieblichen Veränderungen, die in Richtung einer Subjektivierung von Arbeit zu weisen scheinen, erste Anzeichen für einen Umbruch in den bislang paradigmatischen Prinzipien der Rationalisierung von Arbeit. Für viele Produktions-, aber auch Dienstleistungstätigkeiten galt im Rahmen des fordistischen Produktionsmodells, daß der betriebliche Umgang mit Arbeitskraft eher von einem „Objektbezug“ gekennzeichnet war, d.h. - verkürzt - des organisatorischen Versuchs, sich soweit als möglich gerade von den je subjektiven Eigenschaften und Fähigkeiten, aber auch Eigensinnigkeiten und Präferenzen der Beschäftigten unabhängig zu machen. Die Formen sind bekannt: Hierarchien, ausdifferenzierte Arbeitsteilung (versinnbildlicht im Fließband), bürokratische Organisation, Entwicklung von Bearbeitungsroutinen etc.). Die neue zu können, muß zum einen die Zunahme arbeitsinhaltlicher Erwartungen (d.h. der Anspruch, Selbstbestimmungs- und Mitbestimmungswerte auch in der Arbeit zu realisieren) nachgewiesen werden. Zum anderen muß die zunehmende Bedeutung von Arbeits- und Organisationskonzepten, die auf den Selbststeuerungsfähigkeiten, dem Engagement, der Eigeninitiative und der Kommunikations- und Kooperationsbereitschaft der Beschäftigten beruhen, belegt werden“" (Heidenreich 1996, S. 26). 
Logik würde sich demgegenüber gerade durch ihren expliziten und erweiterten „Subjektbezug“" auszeichnen oder - wie es ein vielzitiertes Schlagwort auf den Punkt bringt - : Subjektivität wird „vom Störfaktor zum Potential“"

Lenkt man den Blick nicht alleine auf Veränderungen der Arbeitsstrukturen und der Organisation von Arbeit, sondern auch auf gesellschaftliche Entwicklungen, dann läßt sich mit Heidenreich davon sprechen, daß die These der ,subjektiven Modernisierung (...) auf eine Wahlverwandschaft zwischen wirtschaftlichen Veränderungsprozessen (...) und dem Wandel von Lebens- und Arbeitsstilen (zielt)“ (Heidenreich 1996, S. 32). Und nicht zuletzt diese (unterstellte) „Wahlverwandschaft“ gibt Anlaß zu weitreichenden Überlegungen: Prozesse einer Subjektivierung könnten die Entfremdung in der Arbeit und von der Arbeit aufheben oder im Gegenteil - eine Art „Taylorismus der Seele“ (Zilian 2000) mit sich bringen, indem nunmehr der „ganze Menschen“ mit seiner Subjektivität und Lebenswelt der Ökonomie untergeordnet wird (vgl. Moldaschl 1998). Erste Untersuchungen, die sich vornehmlich mit Hochund Höchstqualifizierte vor allem in wissensintensiven Dienstleistungstätigkeiten befassten, verweisen demgegenüber darauf, daß sich mit der Subjektivierung von Arbeit im Zweifel beides verbindet: Mehr Druck und mehr Freiheit (Glißmann, Peters 2001), mehr Selbstbestimmung und gleichzeitig wachsende Zwänge (vgl. auch die Beiträge in Moldaschl, Voß 2002 sowie Kratzer 2002), kurz: Die Rede ist von den Ambivalenzen einer Subjektivierung und der Klärung ihrer Erscheinungsformen und Ursachen.

\section{Ansatz}

Aufgrund des „Konstruktchrakters“ des Begriffs der Subjektivierung - hier werden sehr unterschiedliche empirische Phänomene in einem Deutungsbegriff gebündelt - lassen sich Tendenzen der Veränderung von Arbeit (und Leben), die in Richtung einer Subjektivierung weisen, nicht direkt untersuchen. Für die empirischen Arbeiten in diesem Berichtsabschnitt ist daher ein Vorgehen leitend, daß Aussagen zum Prozeß der Subjektivierung aus der Beobachtung verschiedener Entwicklungstendenzen sowohl auf der betrieblichen und der individuellen Ebenen und in objektiver sowie subjektiver Perspektive abzuleiten versucht. Diesen Entwicklungstendenzen kommt daher der Stellenwert von Indikatoren zu. 
Indikatoren in diesem Sinne sind auf der betrieblichen Ebene ...:

- die Verbreitung neuer Steuerungsformen in den Unternehmen, die auf die Eigenverantwortlichkeit und Selbstorganisation der Beschäftigten rekurrieren (Vertrauensarbeitszeit und Zielvereinbarungen),

- spezifische Veränderungen der Organisationsstrukturen wie etwa der Abbau von Hierarchieebenen und die Delegation von Entscheidungskompetenz „nach unten“,

- die Verbreitung neuer Arbeitsformen (vor allem Gruppen- und Projektarbeit), die nicht nur die Fähigkeit und Bereitschaft zur Selbstorganisation, sondern auch Kompetenzen der Kommunikation und Kooperation voraussetzen und

- Formen flexibler Arbeitszeitorganisation, die den Beschäftigten Gestaltungsspielräume im Hinblick auf ihren (zeitlichen) Arbeitseinsatz und das Verhältnis von Arbeit und Leben einräumen (Gleitzeit, Arbeitszeitkonten u.a.).

... auf der individuellen Ebene:

- die Verbreitung von Tätigkeiten, die eigenverantwortliches Arbeiten und/oder die unmittelbare Interaktion mit „Kunden“ ${ }^{22}$ beinhalten,

- die Verbreitung von Beschäftigtengruppen mit Gestaltungsspielräumen in bezug auf die Arbeitsausführung oder den Arbeitseinsatz,

- Veränderungen in der Wahrnehmung und Bewertung von Arbeit sowie von Arbeits- und Erwerbsorientierungen, die sich mit wachsenden Ansprüchen an Selbstentfaltung und Selbstverwirklichung in der Arbeit verbinden.

Im Folgenden werden exemplarische Befunde präsentiert, die nur einen Teil der relevanten Indikatoren behandeln. ${ }^{23}$ In der weiteren Ausarbeitung der Berichtsgegenstände sowie des

22 In Anführungszeichen deshalb, weil damit auch personenbezogene Dienstleistungen (wie etwa Pflegetätigkeiten) angesprochen sind, in denen die Rede vom „Kunden“ zwar populär, aber wenig hilfreich ist. Gemeinsam ist solchen personenbezogenen Dienstleistungen jedoch, daß zumindest ein Minimum an subjektiver „Beteiligung“ zwingend erforderlich ist. mens- und Arbeitsorganisation; Beschäftigungsverhältnisse; Zeitmuster) sowie speziell im Rahmen des Themenfeldes erarbeitete Ergebnisse. 
Themenfeldes sollen zusätzliche Indikatoren aufbereitet und eingearbeitet werden: so vor allem eine differenziertere Darstellung neuer Arbeitsformen und leistungspolitischer Konzepte in den Unternehmen, die Veränderung von Qualifzierungsformen und -inhalten sowie Veränderungen in den Arbeits- und Erwerbsorientierungen und Befunde zur Wahrnehmung und Bewertung von Arbeit durch Erwerbstätige.

\subsection{Befunde zur Subjektivierung von Arbeit}

\section{Wandel der Tätigkeitsstrukturen}

Einen ersten Anhaltspunkt ${ }^{24}$ für Tendenzen einer Subjektivierung von Arbeit liefert die Veränderung der Tätigkeitsstrukturen und Qualifikationsanforderungen: ${ }^{25}$ Feststellbar ist ein ungebrochener Trend (der sich in den 90er Jahren noch beschleunigte) zum einen in Richtung personen- und (wissensintensiver) unternehmensbezogener Dienstleistungen und höheren Qualifikationsanforderungen sowie wachsender Anteile an höherqualifizierten Tätigkeiten: Die IAB/Prognos-Projektion zum Qualifikationsbedarf zeigt, daß zwischen 1991 und 1995 der Anteil „produktionsorientierter Tätigkeiten“ (Gewinnen, Herstellen; Maschinen einrichten; Reparieren) von 32,7 auf 30,7\% zurückgeht. Der Anteil „primärer Dienstleistungen“, das sind Handels- und Bürotätigkeiten sowie Allgemeine Dienstleistungen wie Reinigen, Bewirten, Lagern, bleibt mit 43\% konstant, während die „sekundären Dienstleistungen“ (Forschen, Entwickeln; Organisation, Management; Betreuen, Beraten, lehren, Publizieren u.ä.) ihren Anteil von 24,3 auf 26,3\% ausbauen. In der Projektion bis 2010 zeigt sich ein vergleichbares Bild (Rückgang der Produktionstätigkeiten, leichte Zuwächse bei den primären und deutliche Zuwächse bei den sekundären Dienstleistungen), das in der Summe dazu führt - so die Annahmen der Projektion zutreffen -, daß Dienstleistungstätigkeiten insgesamt rund $75 \%$ aller Tätigkeiten ausmachen werden und daß hier insbesondere die personen- oder wissensbasierten Dienstleistungen eine immer größeren Anteil haben könnten (Reinberg 1999).

Daß sich damit zugleich Hinweise auf eine „Subjektivierung von Arbeit“ zeigen, wird deutlich, wenn man sich die Tätigkeitsanforderungen und die Beschäftigtengruppen im Kontext

Vgl. dazu auch das Konzept von Heidenreich, der seine These der ,subjektiven Modernisierung fortgeschrittener Arbeitsgesellschaften“ entlang der Veränderung der Tätigkeitsstrukturen belegt: Er konstatiert zum einen eine Zunahme „kommunikationsintensiverer“ Tätigkeiten - und damit zugleich, daß eine Gruppe von Erwerbstätigkeiten an Bedeutung gewinnt, für die „selbstbestimmtere Arbeitseinstellungen“ wichtig sind (Heidenreich 1996). Ein ähnliches Vorgehen wählte auch Moldaschl (1998). 
sekundärer Dienstleistungen genauer ansieht. Man kann dabei gewissermaßen an zwei Polen ansetzen:

So sind auf der einen Seite Konzepte wie „Interaktionsarbeit“ oder „Emotionsarbeit“ Konzepte, mit denen auf die Implikationen kunden- oder klientenorientierter Arbeit verwiesen wird, die u.a. aus den Besonderheiten eines Arbeitsprozesses bestehen, für den die Interaktion zwischen zwei (oder mehreren) Personen ebenso zentral wie das Einbringen der eigenen Subjektivität (eben etwa Gefühle, Präferenzen etc.) unumgänglich ist (vgl. dazu in einer Deutung aus der Perspektive des Subjektivierungskonzepts: Rieder 2002; vgl. auch Brehm 2001).

Auf der anderen Seite verweist die Forschung zu den Hoch- und Höchstqualifizierten darauf, daß sich diese - und nicht erst seit heute - durch eine ,starke inhaltlich akzentuierte Berufsorientierung; ein hohes, auf Wissen- und Fachkompetenz gestütztes Selbstbewußtsein; eine hohe Sensibilität gegenüber rigiden Organisations- und Kompetenzstrukturen und eine ausgeprägte Reflexivität, die ein individualistisches Interessen- und Handlungskonzept hervorbringt, mit dezidierten Ansprüchen an Selbstentfaltung und Selbstdarstellung in der Arbeit wie im Privatleben“ (Baethge 1994; zit. nach Kleemann u.a. 2002, S. 82f.; vgl. dazu auch Kotthoff 1997; Faust u.a. 2000). Bliebe ein solcher Orientierungsmuster konstant, dann würde es sich zugleich mit der Zunahmen solcher Tätigkeiten mehr und mehr verbreiten.

\section{Wandel der Arbeitsanforderungen}

Eine solche „Expertenorientierung“ dürfte mit den jeweiligen Arbeitsanforderungen korrespondieren: Wesentliches Kennzeichen der Arbeitssituation von vielen Höherqualifizierten, von Experten oder Führungskräften (denen solche Orientierungsmuster unterstellt werden können) ist, daß diese auf der Basis (beruflicher) Qualifikationen sowie extrafunktionaler Kompetenzen und in hoher Eigenständigkeit Anforderungen und Probleme bewältigen (sollen), für die es gerade keine standardisierten Lösungen oder routinisierten Verfahren gibt. Vergleicht man diesbezüglich die Daten der BIBB/IAB-Erhebungen ${ }^{26}$ 1991/92 und 1998/99, dann zeigt sich, daß zum einen der Anteil derjenigen, die an ihrem Arbeitsplatz überwiegend Routineaufgaben oder repetitive Arbeiten verrichten, abnimmt und zugleich mehr Personen

Vgl. auch den Berichtsgegenstand „Qualifikations(niveau) und Arbeitsmarktdynamik“

Zum Datensatz vgl. den Berichtsgegenstand „Qualifikations(niveau) und Arbeitsmarktdynamik“. 
angeben, an ihrem Arbeitsplatz könne (oder müsse) man sich ,immer wieder in neue Aufgaben einarbeiten“ oder „Verfahren verbessern, Neues ausprobieren“:

1991/92 gaben 35\% an, daß ihr Arbeitsplatz sich dadurch auszeichnet, daß praktisch immer oder häufig die „Durchführung bis in Einzelheiten vorgeschrieben“ ist. Dieser Wert sinkt Ende der 90er Jahre auf 31\%. Repetitive Arbeit, also die ausschließliche oder häufige Wiederholung „ein und desselben Arbeitsganges“ kennzeichnet 1991/92 48\% der Arbeitsplätze, bei der nächsten Erhebung sind es nur noch 45\%. Dem steht die Zunahmen des Anteils von Arbeitsplätzen von 28 auf $35 \%$ gegenüber, für die zutrifft, daß man hier praktisch immer oder häufig mit Neuem konfrontiert ist und sich immer wieder einarbeiten muß. Und der Anteil derjenigen, die am Arbeitsplatz „Verfahren verbessern“ bzw. „Neues ausprobieren“ steigt von 43\% 1991/92 auf 47\% 1998/99 (Jansen 2000, S. 58f.).

\section{Wandel der Arbeitsorganisation (neue Arbeitsformen)}

Die Verbreitung neuer Arbeitsformen auf der individuellen Ebene zu erfassen, bereitet erhebliche Schwierigkeiten, die - neben einem generellen Mangel an Daten - insbesondere darauf zurückzuführen sind, daß in der Regel kaum geklärt bzw. kaum zu klären ist, was im einzelnen unter so pauschalen Zuschreibungen wie „Gruppenarbeit“ oder „Projektarbeit“ gemeint ist und mit welchen Implikationen für Art und Umfang der Selbststeuerung sie sich jeweils verbinden.

Richtet sich der Blick demnach nur auf solche Formen von Gruppenarbeit, denen „strukturinnovativer" Charakter (Gerst 1995) bzw. weitergehende Autonomiespielräume zugeschrieben werden, dann bleibt die Realität hinter manchen Erwartungen zurück: So kommt die Struktuberichterstattung des IAT zum Schluß, daß sich zwar der Anteil der Beschäftigten, die in gruppenförmigen Arbeitsstrukturen tätig sind, von insgesamt knapp 7\% im Jahr 1993 auf rund 12\% im Jahr 1998 erhöht hat, daß aber nur bei einem Bruchteil davon auszugehen ist, daß es sich dabei um „teilautonome Gruppenarbeit“ handelt, also um einen Gruppenarbeitstypus, bei dem die Beschäftigten in relativ hohem Maße an arbeitsorganisatorischen und arbeitsprozessuellen Veränderungen beteiligt sind, weitgehend kooperativ agieren und über die unmittelbare Bearbeitung und die Kontrolle der Arbeitsqualität im wesentlichen selbst entscheiden. Insgesamt geben nur etwas mehr als 3 Prozent an, in einer solcher Arbeitsform tätig zu sein (1993: 2,2\%), wobei diese ,ganz eindeutig (...) im Bereich der hochwertigen Tätigkeiten des 
Planens und Konstruierens sowie des Lernens und Beratens (angesiedelt)“ sind (NordhauseJanz, Pekruhl 2000, S. 56).

Erweitert man allerdings die Perspektive auf die Entwicklung der einzelnen Merkmale Kooperation, Partizipation und Autonomie, dann zeigen sich hier deutlich höhere Anteile: Demnach sind im Jahr 1998 49,7\% aller Beschäftigten in Arbeitsstrukturen tätig, die durch Kooperation mit Kollegen geprägt sind, mithin erweiterte Anforderungen an Kommunikations- und Kooperationsbereitschaft und -fähigkeit stellen (1993: 48,7\%). Partizipationsmöglichkeiten haben 47\%, knapp zwei Prozent mehr als sechs Jahre zuvor. Und Gestaltungsspielräume hinsichtlich der Festlegung und Bearbeitung von Aufgaben sowie der Qualitätskontrolle haben 35,7\%, das sind ebenfalls rund 2\% mehr als im Jahr 1993 (Nordhause-Janz, Pekruhl 2000, S. 65). Die Autoren geben allerdings auch Hinweise auf die vermutlich wachsende Heterogenität der Arbeitsstrukturen, die sich als Anzeichen für eine „Polarisierung von Tätigkeitsstrukturen“ interpretieren lassen, da sich für den gleichen Zeitraum auch beobachten läßt, daß Arbeitsstrukturen an Bedeutung gewinnen, die in den Dimensionen Kooperation, Partizipation und Autonomie „besonders negativ ausgeprägt sind. (...) Auf der einen Seite steigt der Anteil derjenigen Beschäftigten, die relativ gut entlohnten, interessanten Tätigkeiten nachgehen und deren Wissen und Können im Arbeitsprozeß produktiv genutzt wird. Auf der anderen Seite nehmen aber auch die schlechtbezahlten Jobs zu, in denen die Arbeit uninteressant und wenig herausfordernd ist und in denen Beschäftigte lediglich zu „funktionieren“ haben, aber selbst nichts zu einer Effizienzsteigerung ihrer Arbeitsabläufe und der Produktionsorganisation insgesamt beitragen können“" (ebd.).

\section{Flexibilisierung (von Beschäftigung und der Arbeitszeit)}

Wachsende Ansprüche an die Selbststeuerung und Selbstorganisation sind jedoch nicht nur mit Veränderungstendenzen der Arbeitsorganisation von Tätigkeits- und Arbeitsanforderungen verbunden, sondern gehen auch mit der Flexibilisierung von Beschäftigung und Arbeitszeit und der damit verbundenen Entgrenzung von Arbeit einher (vgl. Döhl u.a. 2001; Jurzcyk, Voß 2000; Kleemann u.a. 2002, Kratzer 2002) einher. Neue Formen der Arbeitszeitregulierung und der Flexibilisierung des zeitlichen Arbeitseinsatzes „öffnen“ die konkrete Arbeitszeitgestaltung für wechselnde betriebliche Anforderungen (bzw. Markt- oder Kundenanforderungen) oder/und verschiedene individuelle Bedürfnisse und Präferenzen (sowie die Anforderungen und Bedürfnisse der jeweiligen „lebensweltlich Anderen“). Statt mehr oder weniger rigider, an Kollektiven orientierter Zeitstandards, wird die individuelle Arbeitszeit damit 
kontext- und entscheidungsabhängig sowie in Abhängigkeit von alltäglichen Ver- und Aushandlungsprozessen gestellt. Dies gilt insbesondere für spezifische Arbeitszeitformen, die in letzter Zeit verstärkt an Bedeutung gewonnen haben: Gleitzeit, Arbeitszeitkonten und Vertrauensarbeitszeit (vgl. dazu insbesondere das Kapitel zur Flexibilisierung der Arbeitszeit).

\subsection{Zusammenfassung Subjektivierung von Arbeit}

Die Ausführungen verweisen insgesamt vor allem auf die Heterogenität und die Ambivalenz dieser Entwicklung.

So sind eben immer noch $41 \%$ der Beschäftigten im wesentlichen , Repetitivarbeiter“ ${ }^{27}$ Oder: die gleichzeitige Zunahme von Tätigkeitsstrukturen mit einem Mehr an Kooperation, Partizipation und Autonomie und von Tätigkeitsstrukturen, in denen sich in puncto Fremdbestimmung, „Objektbezug“, Entwicklungsperspektiven usw. nichts getan oder die Lage sogar verschlechtert hat und die Anlaß zur These einer „Polarisierung“ gibt (s.o.). Auch scheinen sich alte Segmentationslinien eher zu verschärfen, wenn es vor allem die Mittel- und Höherqualifizierten sind, deren Arbeit organisatorisch ,aufgewertet“ wird und die weiterreichende Gestaltungsspielräume, Lernchancen und Partizipationsmöglichkeiten erhalten. Hier ist ein Trost, daß die Anteile der damit verbundenen Tätigkeiten und auch in der Beschäftigtenstruktur insgesamt steigen, aber eben nur ein schwacher Trost, weil diese Entwicklung nach wie vor auf bestimmte Gruppen mit spezifischer Ressourcenausstattung beschränkt bleibt: Insgesamt gibt es offenkundige Diffusionstendenzen von subjektivierenden Arbeitsanforderungen, deren Reichweite aber - so zumindest Studien zu neotayloristischen Formen von Industrie- (Kurz 1998, Springer 1999) oder Dienstleistungsarbeit (etwa: Voß-Dahm 2002) noch begrenzt bleibt. Für die weitere Entwicklung wäre gerade entscheidend, inwieweit diese Diffusionsprozeß weitergeht oder ob nicht im Gegenteil ganze Erwerbstätigengruppen vom Zug der ,innovativen Arbeitsgestaltung“ abgekoppelt sind oder werden.

Ein ebenso schwacher Trost für diese Gruppen dürfte sein, daß „subjektivierende“ Arbeitsstrukturen nicht nur Chancen, sondern in hohem Maße auch spezifische Risiken beinhalten, insbesondere mit einem steigenden Leistungsdruck einher gehen, Gefahren für Gesundheit und psychische Regeneration mit sich bringen und die Herstellung eines ausgewogenen Ver- 
hältnisses von Arbeit und Leben - vorsichtig formuliert - nicht gerade leichter machen: So betont etwa Jansen, daß abwechslungsreiche und innovative Tätigkeiten nicht nur zu „Lernchancen“ beinhalten, sondern auch zu „Lernstreß“ führen (Jansen 2000, S. 59). Mit höherer Qualifikation und höherer Stellung im Beruf verbindet sich insgesamt auch eine stressigere und belastendere Arbeitssituation wie die Daten der neuen BIBB/IAB-Erhebung zeigen: So geben z.B. über die Hälfte der Facharbeiter und der qualifizierten Angestellten an, starkem Termin- und Leistungsdruck ausgesetzt zu sein (ebd., S. 55) und je höher die berufliche Stellung ist, desto mehr kumulieren die verschiedenen Streß- und Belastungsfaktoren (ebd., S. 56). Daß der Leistungsdruck insgesamt zunehmend dürfte, das zeigen auch andere Untersuchungen, wie etwa die WSI-Betriebsrätebefragung, die - allerdings indirekt, da hier die Frage nach wichtigen Themen der Betriebsratsarbeit gestellt wird - für rund 59\% der Dienstleistungs- und 47\% der Betriebe des Verarbeitenden Gewerbes ein wachsender Leistungsdruck festgestellt wird (vgl. Trautwein-Kalms 2001). ${ }^{28}$

\section{Zusammenführung und Ausblick}

Die vorgestellten Daten und Ergebnisse sowie die detaillierteren Ausführungen der korrespondierenden Berichtsgegenstände geben deutliche Hinweise auf die Verbreitung von grundlegend veränderten Organisationsprinzipien und Strukturen von Arbeit. Sowohl auf der Beobachtungsebene der betrieblichen Organisation von Arbeit als auch auf der individuellen Ebene werden Tendenzen einer fortschreitenden Flexibilisierung und Subjektivierung von Arbeit sichtbar. Diese sind zugleich Ausdruck eines grundlegenden Wandels des fordistischen Produktions- und Sozialmodells, da damit bislang konstitutive Prinzipien der betrieblichen Organisation und Nutzung von Arbeitskraft einer tiefgreifenden Veränderung unterliegen. Die These eines beobachtbaren Umbruchs rekurriert jedoch nicht alleine auf die Beobachtung neuer betrieblicher Strategien der Organisation von Einsatz und Nutzung, sondern auch darauf, daß diese Entwicklungstendenzen in ihren Voraussetzungen und Folgen weit über die unmittelbare betriebliche Ebene hinausreichen: So etwa auf Veränderungen in den Haushaltsund Familienstrukturen, in den Arbeits- und Erwerbsorientierungen, in der institutionellen Regulierung u.a. 
Sichtbar wird jedoch auch, daß Prozesse einer Flexibilisierung und Subjektivierung von Arbeit in eine - bislang nur teilweise entschlüsselte - heterogene und ambivalente Syndromatik von Arbeit münden. Ein durchgängiger Befund ist die wachsende Heterogenität der Erwerbsstrukturen mit häufig polarisierenden Zügen: Darauf deuten die Ergebnisse zur wachsenden Heterogenität innerhalb des flexiblen Beschäftigungssegments ebenso hin wie die zur zeitlichen Flexibilisierung von Arbeit und der damit einhergehenden Polarisierung der Arbeitszeitstrukturen entlang von Qualifikation und Geschlecht. Ebenso zeigen die Befunde zur Subjektivierung von Arbeit, daß der wachsenden Gruppe von Beschäftigten, die mit steigenden Gestaltungsspielräumen und zunehmenden Freiräumen der Selbstorganisation ausgestattet sind, eine nach wie große Gruppe von Beschäftigten gegenüber steht, deren Arbeitssituation durch geringe Spielräume und wenige herausfordernde Arbeitsanforderungen gekennzeichnet ist.

Ambivalenz ist das zweite übergreifende Merkmal, da insbesondere die Höherqualifizierten nicht nur mit fördernden, sondern ganz offenkundig auch mit (über)fordernden Arbeitsbedingungen konfrontiert sind, die häufiger mit Streß und Arbeitsdruck verbunden sind und in lange oder überlange Arbeitszeiten münden. Arbeit dürfte aber auch am „unteren“ Ende ambivalent sein, da hier der „Schutz“, den die institutionelle Fremdorganisation bietet (und der sich z.B. in kürzeren Arbeitszeiten äußert), mit fehlenden oder geringen Entfaltungs- sowie Entwicklungsmöglichkeiten einhergeht und der wachsende Arbeitsdruck auch diese Gruppen nicht ausspart. Und: Zu den ,,alten“ Risiken geringerqualifizierter Arbeit könnten neue Risiken hinzukommen, so etwa die Abkoppelung von der Tendenz der Höherqualifizierung (da diese an bestimmte Tätigkeiten und Arbeitsanforderungen gebunden ist), eine wachsende Prekarität durch den Abbau institutioneller Sicherungssysteme u.a.

Dies wirft die Frage nach den alten, veränderten oder eben auch neuen Segmentationslinien auf, da die Ergebnisse darauf verweisen, daß alte Segmentationsmuster weiterhin wirksam sind, sich zugleich aber neue Differenzierungslinien herausbilden, die „quer“ zu den klassischen Beobachtungsdimensionen der Arbeitsforschung liegen: So ist etwa angesichts der wachsenden Heterogenität innerhalb des flexiblen Beschäftigungssegments eine pauschale Prekaritätsunterstellung sicherlich zu undifferenziert. Oder: Die Unterschiede in der Wahrnehmung von Arbeitszeiten entlang des Ausmaßes an Gestaltungsmöglichkeiten der Arbeitszeit verweisen auf weitere Bestimmungskriterien als nur die Länge der Arbeitszeit u.a.

In dem Maße, in dem sich mit dem Wandel von Arbeit auch neue Fragen an bewährte Unterscheidungen stellen, steht auch das traditionelle „Beobachtungsprogramm“ selbst zumindest 
in Teilen zur Debatte: Das Themenfeld ist in seiner Struktur durch die Beobachtung der betrieblichen Stellgrößen der Organisation von Beschäftigung und Arbeit geprägt: Beschäftigungsverhältnisse, Arbeitszeit(organisation) sowie die Arbeitsorganisation (im engeren Sinne) sind die zentralen Parameter der Organisation von Arbeit - und Grundlage einer eingespielten Arbeitsteilung innerhalb der Arbeits- und Industriesoziologie. Daraus entsteht ein grundlegendes Spannungsverhältnis, das die Aufgabenstellung dieses Themenfeldes auch für die $\mathrm{Zu}-$ kunft kennzeichnet: Aus pragmatischen Gründen erscheint es unerläßlich, sich - zunächst - in den vertrauten Bahnen der Beobachtung von Arbeit zu bewegen, da sich Forschung sowie Arbeitsmarkt- und Sozialberichterstattung größtenteils nach wie vor in jenen Bahnen bewegen. Zugleich muß aber der Blick geöffnet werden für neue Entwicklungen, deren Bedeutung sich erst in einer Perspektive erschließt, die diese Grenzen überschreitet:

Das „Neue“ an der gegenwärtigen Entwicklung besteht zumindest zum Teil gerade darin, daß es die Grenzen zwischen verschiedenen arbeitskraftbezogenen Gestaltungsparametern sind, die neu gezogen und neu kombiniert werden. So könnten z.B. die Schwierigkeiten bei der Einordnung und Bewertung der Teilzeitarbeit - flexibles Beschäftigungsverhältnis oder Arbeitszeitform - auch darauf zurückzuführen sein, daß sie in machen Unternehmen tatsächlich beides ist. Oder: Geht es bei der gegenwärtig vieldiskutierten „Vertrauensarbeitszeit“ tatsächlich um ein neues Konzept der Regulierung von Arbeitszeit oder ist die Entkoppelung der Leistungspolitik von der Arbeitszeit nicht gerade Ausdruck einer Paradoxie, die darin besteht, daß einerseits „Zeit““ als ökonomischer Faktor im Unternehmen eher wichtiger wird, gleichzeitig aber in der Regulation von Arbeit immer unwichtiger zu werden scheint (vgl. dazu Kratzer 2002). Würde man dann nicht die - eben vielleicht viel bedeutsameren - leistungspolitischen Implikationen vernachlässigen, wenn man alleine auf den zeitregulativen Aspekt neuer Arbeitszeitformen schaut (so etwa Haipeter u.a. 2002)?

Weiter gefaßt: Problematisch erscheint die Unterscheidung dreier arbeitskraftbezogener Gestaltungsparamenter und deren analytische Trennung dann, wenn sie mögliche allgemeinere Prinzipien der Rationalisierung von Arbeit (oder auch der individuellen Lebensführung) verschleiern, die gerade nicht an einzelnen Dimensionen ansetzen, sondern sich lediglich in diesen - und eben u.U. auf sehr unterschiedliche Weise - konkretisieren: Erst in dieser Perspektive wäre dann überhaupt erst möglich zu fragen: Haben die flexiblen Arbeitszeiten hochqualifizierter IT-Fachleute und die neo-tayloristische Arbeitsorganisation von angelernten CallCenter-Beschäftigten etwas gemeinsam - und wenn ja was und mit jeweils welchen Folgen? Folgt also aus generalisierbaren Prinzipien ökonomischer Restrukturierung - Globalisierung, 
Dienstleistungsökonomie und Vermarktlichung, Informatisierung usw. - ein neuer Rationalisierungsmodus, in dessen Rahmen zum Beispiel die Bewältigung von Unbestimmtheit im Spannungsfeld zwischen marktlichen Anforderungen, unternehmerischen Imperativen und erweiterten subjektiven Ansprüchen an Arbeit in genereller Weise zur Aufgabe von Arbeitskraft gemacht wird? Ist es ein abstraktes Prinzip wie die „De-Kommodifizierung“ (Bosch 2001) oder die erweiterte Ökonomisierung (etwa: Voß, Pongratz 1998) von Arbeitskraft, das sich sehr unterschiedlich umsetzt?

Die Beantwortung dieser Fragen bleibt der weiteren Berichterstattung vorbehalten. Eine neue - Gemeinsamkeit verschiedenster Arbeitskräftegruppen läßt sich allerdings jetzt schon benennen: Offenkundig führen die öffentliche Diskussion, vermutlich sehr viel unmittelbarer aber die erlebbaren Veränderungen von Wirtschaft, Betrieb und Arbeit zu einer wachsenden Unsicherheit, deren Wahrnehmung eben nicht mehr so eindeutig an etwa Qualifikationsstrufen gebunden ist: Auswertungen der BIBB/IAB-Erhebung zeigen, daß in den 90er Jahren zwar die Gruppe derjenigen wächst, die ihr eigenes Entlassungsrisiko für „eher gering“ hält, zugleich steigt aber auch die Zahl derjenigen, die ihr Entlassungrisiko für ziemlich hoch halten und rapide gesunken ist der Anteil derjenigen, die pauschal von sich behaupten würden, diesbezüglich keiner Gefahr ausgesetzt zu sein (Parmentier 2000, S. 19). Auf der Basis eigener Auswertungen ${ }^{29}$ läßt sich dieser Befund nicht nur bestätigen, sondern auch präzisieren: Während zwar der Anteil derjenigen, die sich große Sorgen (um die Sicherheit des Arbeitsplatzes) machen, insgesamt eher etwas zurückgeht, schrumpft - und zwar deutlicher - der Anteil derjenigen, die sich keine Sorgen machen. Und schaut man sich näher an, wer das ist, dann zeigt sich in überraschender Deutlichkeit, daß es gerade die Mittel- und Höherqualifizierten, die Angestellten und Selbständigen sowie die mit den langen und überlangen Arbeitszeiten sind, die sich ganz offensichtlich zunehmend Sorgen um ihren Arbeitsplatz machen. der Jahre 1984 und 2000. 


\section{Literatur}

Atkinson, J. (1984): Manpower Strategies for Flexible Organisations. In: Personnel Management, vol. 16, no. 8, pp. 28-31.

Baethge, M. (1991): Arbeit, Vergesellschaftung, Identität - Zur zunehmenden normativen Subjektivierung der Arbeit. In: Soziale Welt, Heft 1, 42. Jg., S. 6-19.

Baethge, M. (1999): Subjektivität als Ideologie. Von der Entfremdung in der Arbeit zur Entfremdung auf dem (Arbeits-)Markt. In: G. Schmidt (Hrsg.): Kein Ende der Arbeitsgesellschaft, Berlin, S. 29-44.

Baethge, M.; Baethge-Kinsky, V. (2002): Arbeit - die zweite Chance. Zum Verhältnis von Arbeitserfahrungen und lebenslangem lernen. In: Kompetenzentwicklung 2002. Rückblick - Stand - Ausblick. Münster u.a., S. 69-140.

Bauer, F. u.a. (2002): Arbeits- und Betriebszeiten 2001. Neue Formen des betrieblichen Arbeits- und Betriebszeitenmanagements. Ergebnisse einer repräsentativen Betriebsbefragung. Berichte des ISO 67, Köln.

Bechtle, G.; Lutz, B. (1989): Die Unbestimmtheit post-tayloristischer Rationalisierungsstrategie und die ungewisse Zukunft industrieller Arbeit - Überlegungen zur Begründung eins Forschungsprogramms. In: K. Düll; B. Lutz (Hrsg.): Technikentwicklung und Arbeitsteilung im internationalen Vergleich, Frankfurt/New York, S. 9-91.

Bechtle, G.; Sauer, D. (2001/02): Kapitalismus als Übergang - Heterogenität und Ambivalenz. In: FIAB - Jahrbuch Arbeit-Bildung-Kultur, Band 19/20, 2001/02, S. 49-62.

Beck, U. (1986): Risikogesellschaft - Auf dem Weg in eine andere Moderne, Frankfurt.

Bender, G. (2002): Entstandardisierte Formen der Leistungsbeurteilung - Ein Beispiel und vier Thesen. In: D. Sauer (2002): DIENST - LEISTUNG(S) - ARBEIT, München, S. 21-34.

Berger, P. A.; Hradil, S. (Hrsg.) 1990: Lebenslagen, Lebensläufe, Lebensstile, Soziale Welt, Sonderband 7, Göttingen.

Blanke, K. (1996): Beruf und Familie, In: Blanke, K. u.a.: Zeit im Blickfeld: Ergebnisse einer repräsentativen Zeitbudgeterhebung. Schriftenreihe des Bundesministeriums für Familie, Senioren, Frauen und Jugend, Band 121; Stuttgart, Berlin, Köln.

Bögenhold, D.; Staber, U. (1990): Selbständigkeit als ein Reflex auf Arbeitslosigkeit? Makrosoziologische Befunde einer international-komparativen Studie. In: Kölner Zeitschrift für Soziologie und Sozialpsychologie, Heft 2, S. $265 \mathrm{ff}$.

Böhle, F. (1994): Negation und Nutzung subjektivierenden Arbeitshandelns bei neuen Formen qualifizierter Produktionsarbeit. In: N. Beckenbach; W. van Treeck (Hrsg.): Umbrüche gesellschaftlicher Arbeit, Soziale Welt, Sonderband 9, Göttingen, S. 183-206.

Böhle, F. (2002): Subjektivierung von Arbeit - vom Objekt zum gespaltenen Subjekt. In: M.Moldaschl; G.G. Voß (Hrsg.): Die Subjektivierung von Arbeit, München/Mering.

Bollinger, H. (2001): Neue Formen der Arbeit - neue Formen des Gesundheitsschutzes: Das Beispiel Projektarbeit. In: WSI-Mitteilungen, 11/2001, S. 685-691.

Bosch, G. (2001): Konturen eines neuen Normalarbeitsverhältnisses. In: WSI-Mitteilungen, Heft 4, S. 219-230.

Bosch, G. u.a. (2001): Zur Zukunft der Erwerbsarbeit. Eine Positionsbestimmung auf der Basis einer Analyse kontroverser wissenschaftlicher Debatten. Manusskript, Gelsenkirchen.

Brehm, M. (2001): Emotionen in der Arbeitswelt. In: Arbeit, Heft 3/2001, S. 205-218.

Brose, H.-G. (2000): Einleitung: Die Reorganisation der Arbeitsgesellschaft. In: H.-G. Brose (Hrsg.): Die Reorganisation der Arbeitsgesellschaft, Frankfurt/New York, S. 9-30.

Buch, H.: Ungeschützte Beschäftigungsverhältnisse - Scheinselbständigkeit und geringfügige Beschäftigung auf dem deutschen Arbeitsmarkt, Frankfurt/M. 1999.

Bundesmann-Janßen, J.; Groß, H.; Munz, E. 2000: Arbeitszeit '99, Ergebnisse einer repräsentativen Beschäftigtenbefragung zu traditionellen und neuen Arbeitszeitformen in der Bundesrepublik Deutschland, ISO: Köln.

Büssing, A.; Glaser, J. (1999): Interaktionsarbeit. Konzept und Methode der Erfassung im Krankenhaus. In: Zeitschrift für Arbeitswissenschaft, Heft 3/99, S. 164-173.

Deml, J.; Struck-Möbbeck, O. (1998): Formen flexibler Beschäftigung - Umfang und Regulierungserfordernisse, Supplement der Zeitschrift Sozialismus, Ausgabe 3, Hamburg 1998.

Deutschmann, C. (2001): Die Gesellschaftskritik der Industriesoziologie - ein Anachronismus? In: Leviathan, Heft 1, S. 58-69.

Döhl, V.; Kratzer, N.; Moldaschl, M.; Sauer, D. (2001): Die Auflösung des Unternehmens? - Zur Entgrenzung von Kapital und Arbeit. In: U. Beck; W. Bonß (Hrsg.): Die Modernisierung der Moderne, Frankfurt, S. 219232.

Dörre, K. (2001): Eine arbeitspolitische Debatte in den Gewerkschaften ist überfällig. In: Supplement der Zeitschrift Sozialismus, Heft 9, S. 36-46.

Erlinghagen, M.; Knuth, M. (2001): Keine Spur vom „Turbo-Arbeitsmarkt“ - Arbeitsmarktmobilität und Beschäftigungsstabilität im früheren Bundesgebiet. Arbeitspapier, Gelesenkirchen.

Faust, M.; Jauch, P.; Brünnecke, K.; Deutschmann, Ch. (1994): Dezentralisierung von Unternehmen - Bürokratie- und Hierarchieabbau und die Rolle betrieblicher Arbeitspolitik, München und Mering. 
Faust, M.; Jauch, P.; Notz, P. (2000): Befreit und entwurzelt - Führungskräfte auf dem Weg zum ,internen Unternehmer", München und Mering.

Föste, W. u.a. (2001): Flexibilität und Sicherheit am Arbeitsmarkt. Schriftenreihe des Forschungsinstituts für Ordnungspolitik, Band 2. Frankfurt/ New York.

Frick, S. u.a. (1998): Möglichkeiten zur Verbesserung des Umfeldes für Existenzgründungen und Selbständige. Wege zu einer neuen Kultur der Selbständigkeit. Untersuchungen des RWI, Heft 25, Essen.

Funder, M. (1999): Paradoxien der Reorganisation, München und Mering.

Garhammer, M. (1999): Wie Europäer ihre Zeit nutzen, Zeitstrukturen und Zeitkulturen im Zeichen der Globalisierung, Berlin.

Garhammer, M. (2000): Arbeitszeit und Zeitwohlstand im internationalen Vergleich - eine Schlüsselfrage für die Lebensqualität in Europa, Bamberger Beiträge zur Europaforschung und zur internationalen Politik Nr. $5 / 2000$.

Gerst, D. (1998): Selbstorganisierte Gruppenarbeit - Gestaltungschancen und Umsetzungsprobleme, Broschüre, Göttingen.

Gerst, D. u.a. (1995): Gruppenarbeit in den 90ern: Zwischen strukturkonservativer und strukturinnovativer Gestaltungsvariante. In: SOFI-Mitteilungen, 22/1999, S. 3965.

Glißmann, W.; Peters, K. (2001): Mehr Druck durch mehr Freiheit - Die neue Autonomie in der Arbeit und ihre paradoxen Folgen, Hamburg.

Groß, H.; Munz, E. (2000): Arbeitszeit 2000 in Nordrhein-Westfalen, ISO, Köln 2000.

Haak, C.; Schmid, G. (2001): Arbeitsmärkte für Künstler und Publizisten: Modelle der künftigen Arbeitswelt? In: Leviathan, Heft 2, S. 156-178.

Haipeter , T. u.a. (2002): Vertrauensarbeitszeit. Analyse eines neuen Rationalisierungskonzepts. In: Leviathan, Heft 3/2002, S. 360-383.

Hartz, P. (1996): Das atmende Unternehmen. Jeder Arbeitsplatz hat einen Kunden. Frankfurt/ New York.

Heidenreich, M. (1996): Die subjektive Modernisierung fortgeschrittener Arbeitsgesellschaften. In: Soziale Welt, Heft 1, S. 24-43.

Hensche, D.2001: Chancen für eine zukünftige gewerkschaftliche Arbeitszeitpolitik, in: WSI-Mitteilungen, 10/2001, 602-605.

Herrmann-Stojanov, I.; Rinderspacher, J.P. (2001):Zeitwohlstand im Umbruch? Ambivalente Relationen zwischen alten und neuen Zeitinstitutionen, in: WSI-Mitteilungen 10/2001, 636-642.

Hielscher, V. 2000: Entgrenzung von Arbeit und Leben?, Die Flexibilisierung von Arbeitszeiten und ihre Folgewirkungen für die Beschäftigten, Eine Literaturstudie, Berlin.

Hielscher, V.; Hildebrandt, E. (1999): Zeit für Lebensqualität - Auswirkungen verkürzter und flexibilisierter Arbeitszeiten auf die Lebensführung, Berlin.

Hielscher, V.; Hildebrandt, E. (1999): Zeit für Lebensqualität. Auswirkungen verkürzter und flexibilisierter Arbeitszeiten auf die Lebensführung, Berlin.

Hoffmann, E.; Walwei, U. (1998): Längerfristige Entwicklung von Erwerbsformen in Westdeutschland, IABkurzbericht, Nr. 2, Nürnberg.

Hoffmann, E.; Walwei, U. (2002): Wandel der Erwerbsformen: Was steckt hinter den Veränderungen? In: Kleinhenz, G. (Hrsg.): IAB-Kompendium Arbeitsmarkt- und Berufsforschung. BeitrAB 250, Nürnberg, S. $135-144$

Holtgrewe, U.; Voswinkel, S. (2002 ): Kundenorientierung zwischen Mythos, Organisationsrationalität und Eigensinn der Beschäftigten. In: D. Sauer (Hrsg.): Dienst - Leistung(s) - Arbeit, München, S. 99-118.

Holz, E. (2000): Zeitverwendung in Deutschland - Beruf, Familie, Freizeit. Band 13 der Schriftenreihe Spektrum Bundesstatistik, Wiesbaden.

Jahn, E.; Rudolph, H. (2002): Zeitarbeit: Auch für Arbeitslose ein Weg mit Perspektive. IAB-Kurzbericht 20/28.8.2002.

Jansen, R. (2000): Arbeitsbedingungen, Arbeitsbelastungen und Veränderungen auf betrieblicher EbeneIn: Dostal, W.; Jansen, R.; Parmentier, K. (Hrsg.): Wandel der Erwerbsarbeit: Arbeitssituation, Informatisierung, berufliche Mobilität und Weiterbildung. BeitrAB231, Nürnberg, S. 39-66.

Junge, M. (1996): Individualisierungsprozesse und der Wandel von Institutionen - Ein Beitrag zur Theorie reflexiver Modernisierung. In: KZfSS, Heft 4, S. 728-747.

Jurczyk, K.; Voß, G. (2000): Entgrenzte Arbeitszeit - Reflexive Alltagszeit. Die Zeiten des Arbeitskraftunternehmers. In: E. Hildebrandt (in Zusammenarbeit mit G. Linne) (Hrsg.): Reflexive Lebensführung, Berlin, S. 151-206.

Klammer, U.; Tillmann, K. (2001): Flexicurity: Soziale Sicherung und Flexibilisierung der Arbeits- und Lebensverhältnisse. Hektographierter Bericht.

Kleemann, F.; Matuschek, I.; Voß, G.: Subjektivierung von Arbeit - Ein Überblick zum Stand der soziologischen Diskussion. In: Moldaschl, M.; Voß, G. (Hrsg.): Subjektivierung von Arbeit, München und Mering, S. 53-100.

Köhler, Ch.; Preisendörfer, P. (1989): Innerbetriebliche Arbeitsmarktsegmentation in Form von Stamm- und Randbelegschaften? In: Ch. Köhler; P. Preisendörfer (Hrsg.): Betrieblicher Arbeitsmarkt im Umbruch, Frankfurt/New York 1989, S. 149-173. 
Kotthoff, H. (1997): Führungskräfte im Wandel der Firmenkultur - Quasi-Unternehmer oder Arbeitnehmer? Berlin.

Kratzer (2002): Rationalisierung mit (un)bestimmten Folgen. Berlin, im Erscheinen.

Kratzer, N.; Döhl, V. (2000): Flexibilisierung des Fachkräfteeinsatzes. In: B. Lutz u.a. (Hrsg.): Industrielle Fachkräfte für das 21. Jahrhundert, Frankfurt/New York 2000, S. 239-278.

Kratzer, N.; Döhl, V.; Sauer, D. (1998): Arbeit im Wandel - Sozialberichterstattung vor neuen Herausforderungen. In: ISF München u.a. (Hrsg.): Jahrbuch Sozialwissenschaftliche Technikberichterstattung, Sonderband: Beobachtungsfeld Arbeit, Berlin, S. 97-127.

Kurz, C. (1998): Repetitivarbeit - unbewältigt. Betriebliche und gesellschaftliche Entwicklungsperspektiven eines beharrlichen Arbeitstyps, Berlin.

Lutz, B. (1984): Der kurze Traum immerwährender Prosperität - Eine Neuinterpretation der industriellkapitalistischen Entwicklung im Europa des 20. Jahrhunderts, Frankfurt/New York.

Lutz, B.: Arbeitsmarktstruktur und betriebliche Arbeitskräftestrategie - Eine theoretisch-historische Skizze zur Entstehung betriebszentrierter Arbeitsmarktsegmentation, Frankfurt/New York 1987.

Matthes, J. (1982): Krise der Arbeitsgesellschaft. Verhandlungen des 21. Deutschen Soziologentages in Bamberg 1982, Frankfurt/New York 1992.

Matthies, H.; Mückenberger, U.; Offe, C.; Peter, E.; Raasch, S. (1994): Arbeit 2000 - Anforderungen an eine Neugestaltung der Arbeitswelt, Hamburg.

Moldaschl, M. (1994): „Die werden zur Hyäne“ - Erfahrungen und Belastungen in neuen Arbeitsformen. In: M. Moldaschl; R. Schultz-Wild (Hrsg.): Arbeitsorientierte Rationalisierung, Frankfurt/New York, S. 105-149.

Moldaschl, M. (1998): Internalisierung des Marktes - Neue Unternehmensstrategien und qualifizierte Angestellte. In: ISF-München u.a. (Hrsg.): Jahrbuch Sozialwissenschaftliche Technikberichterstattung 1997 Schwerpunkt: Moderne Dienstleistungswelten, Berlin, S. 197-250.

Moldaschl, M. (2002): Subjektivierung - eine neue Stufe der Entwicklung der Arbeitswissenschaften? In: M. Moldaschl; G.G.Voß (2002): Subjektivierung von Arbeit, München,/Mering.

Moldaschl, M.; Sauer, D. (2000): Internalisierung des Marktes - Zur neuen Dialektik von Kooperation und Herrschaft. In: H. Minssen (Hrsg.): Begrenzte Entgrenzungen, Berlin, S. 205-224.

Moldaschl, M.; Voß, G.G. (2002): Subjektivierung von Arbeit, München,/Mering.

Mückenberger, U. (1985): Die Krise des Normalarbeitsverhältnisses - Hat das Arbeitsrecht noch Zukunft? In: Zeitschrift für Sozialreform, Hefte 7 und 8.

Nordhause-Janz, J.; Pekruhl, U. (2000): Managementmethoden oder Zukunftskonzepte? - Zur Entwicklung von Arbeitsstrukturen und von Gruppenarbeit in Deutschland. In: J. Nordhause-Janz; U. Pekruhl. (Hrsg.): Arbeiten in neuen Strukturen? München/Mering, S. 13-68.

Osterland, M. (1990): „Normalbiographie“ und Normalarbeitsverhältnis“. In: P. Berger; S. Hradil (Hrsg.): Lebenslagen - Lebensläufe - Lebensstile, Soziale Welt, Sonderband 7, Göttingen, S. 351-362.

Parmentier, K. (2000): Erwerbsarbeit im Spiegel der BIBB/IAB-Erhebungen 1999/1992. In: Dostal, W.; Jansen, R.; Parmentier, K. (Hrsg.): Wandel der Erwerbsarbeit: Arbeitssituation, Informatisierung, berufliche Mobilität und Weiterbildung. BeitrAB231, Nürnberg, S. 9-38.

Promberger, M. (2001): Industriebeschäftigte in hochflexiblen Arbeitszeitarrangements. In: WSI-Mitteilungen, 10/2001, 626-631.

Reinberg, A. (1999): Der qualifikatorische Strukturwandel auf dem Arbeitsmarkt - Entwicklungen, Perspektiven, und Bestimmungsgründe. In: MittAB 4/99, S. 434-447.

Rieder, K. (2002): Seiner eigenen Subjektivität verhaftet sein. Zum Machttypus der Subjektivierung in der Krankenpflege. In: Moldaschl, M.; Voß, G. (Hrsg.): Subjektivierung von Arbeit, München und Mering, S. 177194.

Röttger, B. (2001/02): Nachfordistisches Produktionsmodell - „,schmetternde Ouvertüre“ einer neuen Formation des Kapitalismus? Insignien einer transnationalen Produktionsweise. In: FIAB - Jahrbuch Arbeit-BildungKultur, Band 19/20, 2001/02, S. 85-100.

Sauer, D.; Döhl, V. (1997): Die Auflösung des Unternehmens? - Entwicklungstendenzen der Unternehmensreorganisation in den 90er Jahren. In: ISF-München u.a. (Hrsg.): Jahrbuch Sozialwissenschaftliche Technikberichterstattung 1996 - Schwerpunkt: Reorganisation, Berlin, S. 19-76.

Sauer, D.; Döhl,V. (1994): Kontrolle durch Autonomie. In: Sydow,J.;Windeler,A (Hrsg.):Management in internationalen Beziehungen.Opladen, 258-274.

Schienstock, G. (1998): Flexibilisierung in der Informationsgesellschaft. In: H.-G. Zilian; J. Flecker (Hrsg.): Flexibilisierung - Problem oder Lösung? Berlin, S. 163-174.

Schmidt, G. (1999): Kein Ende der Arbeitsgesellschaft - Überlegungen zum Wandel des Paradigmas der Arbeit in „frühindustrialisierten Gesellschaften“ am Ende des 20. Jahrhunderts. In: G. Schmidt (Hrsg.): Kein Ende der Arbeitsgesellschaft, Berlin, S. 9-28.

Schmiede, R. (1996): Informatisierung und gesellschaftliche Arbeit. Strukturveränderungen von Arbeit und Gesellschaft. In: WSI-Mitteilungen, Heft 9/1996, S. 533-544.

Schmiede, R. (Hrsg.) (1996): Virtuelle Arbeitswelten. Arbeit, Produktion und Subjekt in der „Informationsgesellschaft", Berlin.

Schreyer, F. (2000): „Unsichere“ Beschäftigung trifft vor allem die Niedrigqualifizierten. IAB-Kurzbericht, Nr. $15 / 31.10 .2000$. 
Schumann, M. (2001): Kritische Industriesoziologie - Neue Aufgaben. In: SOFI-Mitteilungen, Heft 29, S. 9397.

Schumann, M.; Baethge-Kinsky, V.; Kuhlmann, M.; Kurz, C.; Neumann, U. (1994): Trendreport Rationalisierung, Berlin.

Schumann, M; Gerst, D. (1997): Produktionsarbeit - Bleiben die Entwicklungstrends stabil? In: Ifs; INIFES; ISF; SOFI (Hrsg.): Schwerpunkt: Reorganisation, S.131-167.

Senatsverwaltung für Arbeit, Berufliche Bildung und Frauen (Hrsg.) (1998): Die Sackgassen der Zukunftskommission - Streitschrift wider die Kommission für Zukunftsfragen der Freistaaten Bayern und Sachsen, Schriftenreihe der Senatsverwaltung für Arbeit, Berufliche Bildung und Frauen, Nr. 33, Berlin.

Sengenberger, W. (1987): Struktur und Funktionsweise von Arbeitsmärkten - Die Bundesrepublik Deutschland im internationalen Vergleich, Frankfurt/New York.

Springer, R. (1999): Rückkehr zum Taylorismus - Arbeitspolitik in der Automobilindustrie am Scheideweg, Frankfurt/New York.

Trautwein-Kalms, G. (1995): Ein Kollektiv von Indivdualisten? - Interessenvertretung neuer Beschäftigtengruppen, Berlin.

Trautwein-Kalms, G. (1995): Ein Kollektiv von Indivdualisten? - Interessenvertretung neuer Beschäftigtengruppen, Berlin.

Vieth, P. (1995): Kontrollierte Autonomie - Neue Herausforderungen für die Arbeitspsychologie, Heidelberg.

Voß, G. (1998): Die Entgrenzung von Arbeit und Arbeitskraft - Eine subjektorientierte Interpretation des Wandels der Arbeit. In: MittAB, Heft 3, S. 473-487.

Voß, G.; Pongratz, H. (1998): Der Arbeitskraftunternehmer - Eine neue Grundform der „Ware Arbeitskraft“"? In: KZfSS, Heft 1, S. 131-158.

Voß-Dahm, D. (2002): der Einfluß unterschiedlicher Einkaufs- und Verkaufsstrategien des Einzelhandels auf die Arbeits- und Leistungsanforderungen von Beschäftigten. In: D. Sauer (2002): DIENST - LEISTUNG(S) ARBEIT, München, S. 163-180..

Wagner, A. (2001): Entgrenzung der Arbeit und der Arbeitszeit. In: Arbeit, Heft 4/2001, S. 365-378.

Wagner, A. 1999/2000: Arbeit ohne Ende?, Über die Arbeitszeiten hochqualifizierter Angestellter, IAT Jahrbuch 1999/2000, 258-275.

Wolf, H. (1999): Arbeit und Autonomie - Ein Versuch über die Widersprüche und Metamorphosen kapitalistischer Produktion, Münster.

Zilian, H.G. (2000): Taylorismus der Seele. In: Österreichische Zeitschrift für Soziologie, Heft 2, S. 75-97.

Zukunftskommission (Kommission für Zukunftsfragen der Freistaaten Bayern und Sachsen) (1996): Erwerbstätigkeit und Arbeitslosigkeit in Deutschland. Entwicklung, Ursachen und Maßnahmen - Teil I: Entwicklung von Erwerbstätigkeit und Arbeitslosigkeit in Deutschland und anderen frühindustrialisierten Ländern, Bonn 1996. 